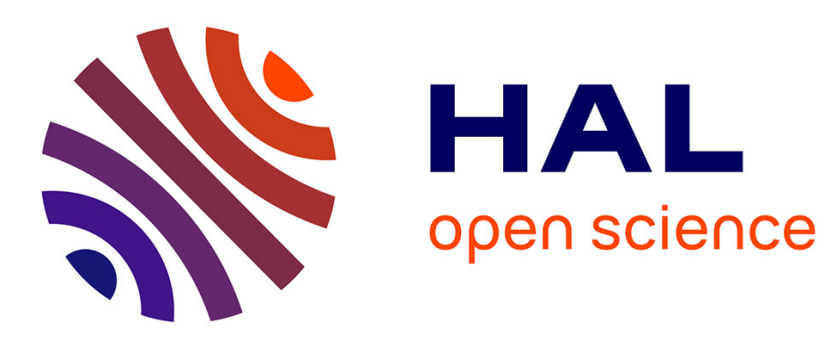

\title{
Rapid characterization of the fatigue limit of additive-manufactured maraging steels using infrared measurements
}

\author{
Corentin Douellou, Xavier Balandraud, Emmanuel Duc, Benoit Verquin, \\ Fabien Lefebvre, Frédéric Sar
}

\section{To cite this version:}

Corentin Douellou, Xavier Balandraud, Emmanuel Duc, Benoit Verquin, Fabien Lefebvre, et al.. Rapid characterization of the fatigue limit of additive-manufactured maraging steels using infrared measurements. Additive Manufacturing, 2020, 35, pp.101310. 10.1016/j.addma.2020.101310 . hal03039283

\section{HAL Id: hal-03039283 \\ https://hal.uca.fr/hal-03039283}

Submitted on 3 Dec 2020

HAL is a multi-disciplinary open access archive for the deposit and dissemination of scientific research documents, whether they are published or not. The documents may come from teaching and research institutions in France or abroad, or from public or private research centers.
L'archive ouverte pluridisciplinaire HAL, est destinée au dépôt et à la diffusion de documents scientifiques de niveau recherche, publiés ou non, émanant des établissements d'enseignement et de recherche français ou étrangers, des laboratoires publics ou privés.

\section{(c)(1)}

Distributed under a Creative Commons Attribution| 4.0 International License 


\title{
Rapid characterization of the fatigue limit of additive- manufactured maraging steels using infrared measurements
}

Corentin Douellou ${ }^{\mathrm{a}}$, Xavier Balandraud ${ }^{\mathrm{a},}$, Emmanuel Duc $^{\mathrm{a}}$, Benoit Verquin ${ }^{\mathrm{b}}$, Fabien Lefebvre ${ }^{\mathrm{b}}$, Frédéric Sar ${ }^{\mathrm{c}}$

a Université Clermont Auvergne, CNRS, SIGMA Clermont, Institut Pascal, F-63000 ClermontFerrand, France

${ }^{\mathrm{b}}$ Cetim, 60304 Senlis, France

c AddUp, 63118 Cébazat, France

* Corresponding author. Email address: xavier.balandraud@ sigma-clermont.fr

\begin{abstract}
This paper deals with the fatigue performance of maraging steels manufactured by Powder Bed Fusion using a laser beam (L-PBF). The objective of the study was to develop a method for the rapid and reliable characterization of the produced material's fatigue limit using infrared (IR) thermography. Preliminary conventional fatigue tests were performed, revealing two distinct populations among the printed specimens depending on their locations on the building plate. Next, fatigue tests instrumented by IR camera were processed using heat source reconstruction to measure the mechanical dissipation due to fatigue damage. A statistical model was then proposed to identify the fatigue limit of the material. Finally, a practical application was performed to compare different manufacturing strategies using the same powder, opening perspectives for the rapid optimization of the printing process with respect to the fatigue performance of the parts produced.
\end{abstract}

Keywords: Powder Bed Fusion; Maraging steel; Fatigue; Infrared thermography; Heat source reconstruction 


\section{Introduction}

Additive manufacturing (AM) is a group of manufacturing technologies all based on the same principle: a digital Computer-Aided Design model is sliced into numerous layers and physically reconstructed layer by layer according to one of the seven AM categories (see Ref. [1]). Among these categories, Powder Bed Fusion with laser beam (L-PBF) also known as Laser Beam Melting or Selective Laser Melting offers interesting opportunities for the manufacture of complex metallic parts for industries in the aeronautical, space, defense or medical sectors, for example. Metallic powder layers (typically 20 to $100 \mu \mathrm{m}$ thick) are selectively melted by a laser beam, from the first layer deposited on the building plate and then layer by layer until the whole mechanical part is manufactured; see Section 2.1 for more details about the process. The opportunities presented by this technology are accompanied by challenging constraints. In particular, the definition of manufacturing parameters, in a broad sense, is complex. Numerous parameters (such as laser power and speed, scan path strategy, layer thickness, powder characteristics, to cite but a few) have a significant impact on the manufactured product quality. The NIST report by Mani et al. [2] provides an accurate review of all the aspects involved in the control of powder bed fusion processes to attain satisfactory product quality. This quality comprises several aspects: geometrical accuracy, physical and material health (porosity, residual stress, etc.) and of course the mechanical properties that are required to comply with the standards of the industrial sector concerned. Making general conclusions about the mechanical performances of L-PBF parts is challenging, since the final properties depend not only on the powder but also on the whole manufacturing process and post-process. Properties might also vary from one printing machine to another, and even from one part to another on the building plate of a given machine. The process being relatively new, its understanding is not yet deep enough to obtain reliable mechanical properties. However, this understanding has increased considerably in the past few years thanks to the prolific research carried out in the metallic AM field. Herzog et al. [3] and Debroy et al. [4] reviewed the literature concerning the metallurgical, physical and mechanical properties of AM metallic parts. They report that the violent thermal history of the matter during the process leads 
generally to a fine and oriented microstructure and therefore to parts with high hardness. As a consequence, yield and ultimate tensile stresses are often shown to reach higher values than normal. Porosities due to a localized lack of fusion during the process have, however, a strong impact on the ultimate strain and the fatigue life. The fatigue response of metals manufactured using L-PBF has not been extensively studied until very recently [5-18]. Even though toughness is generally high, fatigue performances appear to remain inferior to those obtained by conventional means. Fatigue life is particularly affected by the roughness $[3-5,9]$ and by the number of porosities (as well as by their morphology, size and location within the parts). Shamsaei, Yadollahi et al. in Refs $[7,8]$ and Masuo et al. in Ref. [7] studied the differences between the failure mechanisms of AM and conventional parts, and discuss the challenges of implementing fatigue requirements in part design and process setup.

The present paper focuses on the fatigue performance of maraging steel manufactured by L-PBF. Maraging - a portemanteau word for "martensite" and "aging" - steel is an interesting class of material in metallic L-PBF field as it combines good weldability and interesting mechanical properties (high strength and good ductility) after aging heat treatment. The objective of our study was to develop a method for the rapid and reliable characterization of the calorimetric signature of fatigue damage using infrared (IR) thermography, with the long-term objective of optimizing the printing process with regard to the fatigue performance of the material produced. By "calorimetric", we mean here the heat power density (in $\mathrm{W} / \mathrm{m}^{3}$ ) corresponding to the mechanical dissipation (or intrinsic dissipation) associated with fatigue damage. It is worth noting that since IR thermography basically provides temperature fields (in ${ }^{\circ} \mathrm{C}$ or $\mathrm{K}$ ) at the specimen surface, specific data processing is required to "convert" the thermal input data into such a calorific quantity.

The thermal signature of a material's response to fatigue loading can be detected by thermocouples, pyrometry or IR thermography. At the beginning of the last century, Stromeyer had already observed that the cyclic mechanical loading of a material is accompanied by self-heating [19]. The study of this phenomenon and the link with the fatigue limit of the material was not developed before the 1980s. Luong [20, 21] and La Rosa and Risitano [22] published in the 90s the bases of fatigue limit 
evaluation through thermographic measurement: the idea is to identify the stress level above which significant self-heating is detected. Doudard et al. [23, 24] and Munier et al. [25, 26] have carried out extensive work on the understanding of the damage mechanisms (microplasticity) which lead to selfheating. In particular, Munier et al. [25] worked on the differences between the two thermal regimes in the self-heating response, namely below and above the fatigue limit of the material. Teng et al. [27] proposed a procedure to determine the Wöhler curve by IR thermography. Akai et al. [28] used high spatial resolution thermography for the observation of slip bands in 316L austenitic stainless steel (SS) under fatigue loading. Finally, Cao et al. [29] advantageously used the self-heating approach for the comparison of AM and rolled 316L SS, and concluded that the former has a greater fatigue limit than the latter. In this context, the present study proposes to develop a heat source reconstruction (HSR) approach [30] to measure the calorimetric signature of the fatigue damage in L-PBF maraging steel.

The application of HSR to the thermomechanics of materials is justified by the fact that temperature variations in a specimen under mechanical loading are not only due to its mechanical response. Indeed, heat diffusion inside the specimen and heat exchanges with the environment (ambient air, jaws of the testing machine) strongly impact the temperature fields. Chrysochoos et al. developed HSR techniques, based on the heat diffusion equation, to identify the "internal" heat sources produced or absorbed by the material from the temperature fields captured by IR thermography at the surface of a specimen under mechanical loading [30-31]. The present paper is focused on measuring and analyzing that part of the internal heat sources which is due to fatigue damage (i.e. the mechanical dissipation, the other part being due to thermoelastic coupling, see Section 4), with repeatability tests and a statistical analysis of the results.

Note finally that conventional fatigue tests are generally long (several months to obtain the S-N plot of a material) and costly, especially with L-PBF specimens (several thousands of dollars/euros for the manufacturing of the specimen set). The rapid and robust characterization of the material's fatigue performances using IR thermography opens perspectives for a "rapid" optimization, depending on the manufacturing process parameters. 
The paper is organized as follows. Section 2 describes the two experimental setups considered during the study. Conventional fatigue tests are first analyzed in Section 3, including a discussion on the S-N plot obtained and a fractography analysis. The main part of the study then deals with fatigue tests instrumented by IR camera. Section 4 provides some background about HSR and its application to mechanical dissipation identification. Sections 5 and 6 present the calorimetric results and their statistical analysis in terms of fatigue limit assessment and comparison between several criteria. Finally, Section 7 presents a practical application for the comparison of different manufacturing strategies using the same maraging steel powder.

\section{Experimental setups}

\subsection{Material and sattaintpecimens}

All the specimens in the study were manufactured by the Addup Company of Cébazat, France, from 18Ni300 maraging steel powder using a FormUp® 350 printing machine. The machine features a $500 \mathrm{~W} \mathrm{Yb}$ fiber laser, a scan speed of up to $10 \mathrm{~m} / \mathrm{s}$ and a programmable layer thickness of between 20 $\mu \mathrm{m}$ and $100 \mu \mathrm{m}$. Solidified matter was additively produced using the L-PBF process, whose principle is illustrated in Fig. 1. A metallic powder bed is placed on a building plate, then a laser beam selectively melts the powder to create the first solidified layer. The building plate then moves down in the $\mathrm{z}$-direction and a new powder bed is applied over the first layer. The operation is repeated until the complete part is built. With each new layer, several already solidified layers are generally re-melted during the laser passage. More generally, high temperature gradients and high cooling rates occur during the L-PBF process, influencing the final quality of the solidified matter. An inert gas flow is generally employed during the process and influence the "smoke" production accompanying metal melting (sparks, spatter and vapor generation) and thus the porosity formation mechanisms [32, 33]. 
Argon was used during the elaboration of the maraging specimens tested in the present study. The same printing strategy was applied to all the specimens. Two printing zones were used on the building plate: see Fig. 2(a). They are designated $\mathrm{L}$ and $\mathrm{R}$ in the following, and correspond to the input and output zones of the gas flow, respectively. The specimen manufacturing steps are illustrated in Figs. 2(b) and (c). The specimens were first printed in the form of vertical plates $(1.4 \mathrm{~mm}$ in thickness, powder deposition direction from left to right in Fig. 2(a), laser propagation from right to left with $45^{\circ} / 135^{\circ}$ alternation with respect to the $\mathrm{x}$-direction between two consecutive layers), then stress relieved $\left(3\right.$ hours at $580^{\circ} \mathrm{C}$ ), and separated from the building plate. Other details regarding manufacturing parameters and strategies cannot be disclosed for reasons of confidentiality. Next, lateral surfaces were ground, leading to a plate thickness of $1 \mathrm{~mm}$. Finally, specimens were machined to the desired shape by electrical discharge machining (EDM). No annealing or hot isostatic pressing (HIP) treatment was performed. Note that the ultimate tensile strength measured by the manufacturer AddUp for the obtained material was equal to $1360 \mathrm{MPa}$ in the $\mathrm{x} / \mathrm{y}$ directions (perpendicular to the printing direction $\mathrm{z}$ ). Two specimen geometries were considered due to the use of two different testing setups, as explained in the next section.

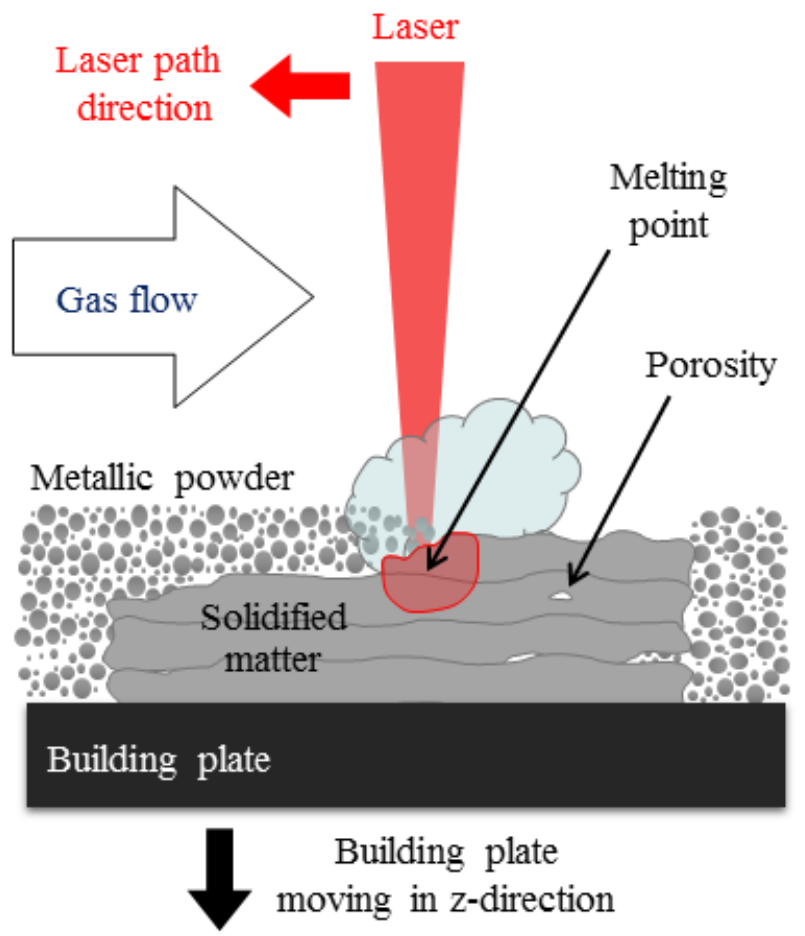

Fig. 1. Principle of the L-PBF manufacturing. 

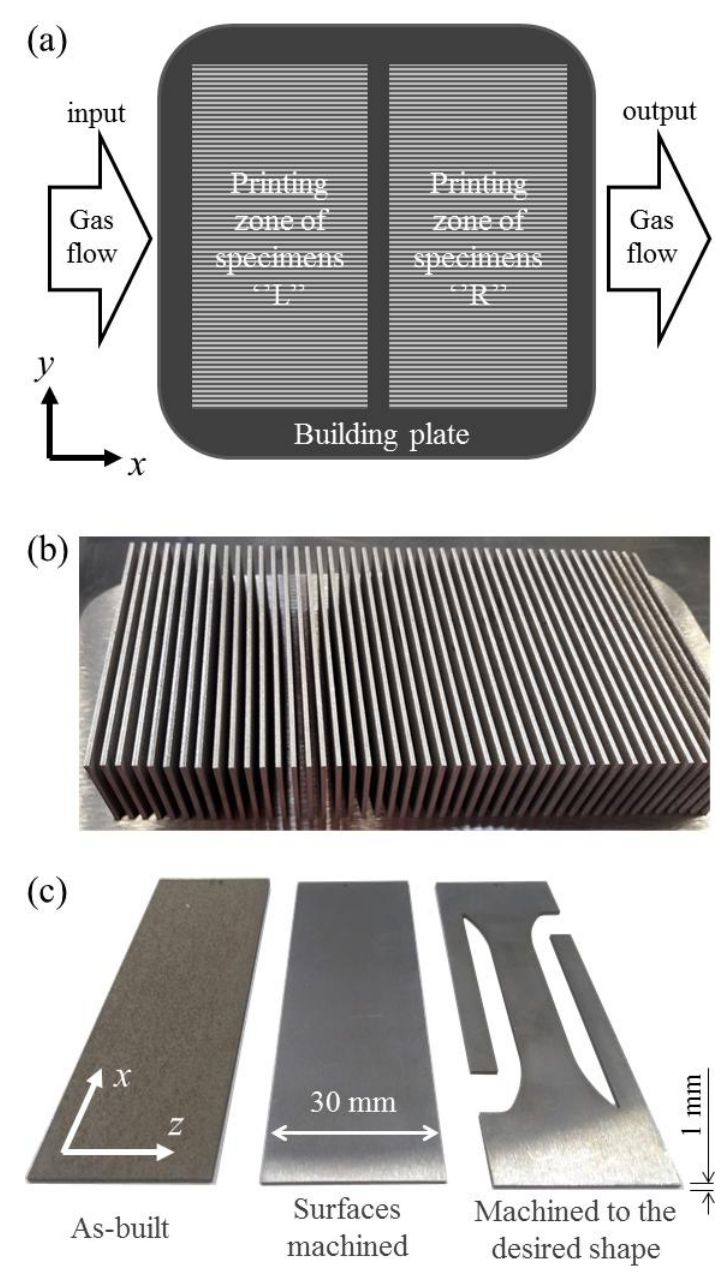

Fig. 2. Specimen manufacturing: (a) schematic view of the two printing zones on the building plate;

(b) photograph of as-built plates on the building plate; (c) photograph of specimens at different manufacturing stages.

\subsection{Loading and measurement}

Fig. 3 presents the two experimental setups used during the study:

- a ZwickRoell Vibrophore testing machine with a capacity of $20 \mathrm{kN}$ was employed for conventional fatigue tests (Fig. 3(a)) in order to construct the S-N curve of the material. Adjustable jaws were used to mount the specimens in the machine. The loading frequency obtained by mechanical resonance was $66 \mathrm{~Hz} \pm 1 \mathrm{~Hz}$. Calibration was performed for a range from $0 \mathrm{kN}$ to $10 \mathrm{kN}$ according to the ISO 7500-1:2018 standard (class 1 equipment) [34]; 
- a $\pm 15 \mathrm{kN}$ MTS machine was employed for fatigue tests instrumented by IR camera (Fig. 3(b)) in order to measure the mechanical dissipation associated with fatigue damage. For thermal measurements, specimens were first covered by a thin coat of matt black paint to maximize thermal emissivity. To limit reflections in the IR range, the specimen's close environment was covered by black cardboard sheets and curtains. A cardboard tunnel (not shown in the picture) was also placed between the IR camera and the observed zone. The testing machine, IR camera and computers were turned on three hours before the experiments began in order to ensure the steady thermal state of the testing room. Once a specimen was clamped in the grips of the testing machine, a waiting time of $15 \mathrm{~min}$ was respected before applying the mechanical loading, in order to start from a steady thermal state of the specimen in its environment. Finally, note that nobody was present in the room during the tests in order to minimize air flow. 
(a)

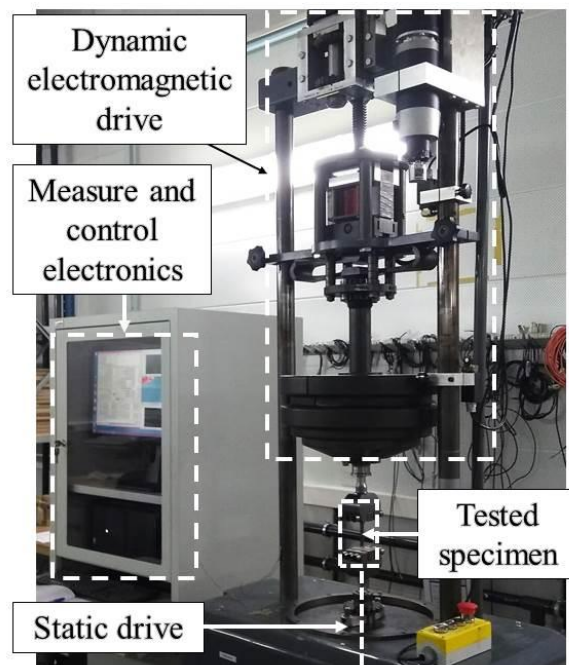

(c)

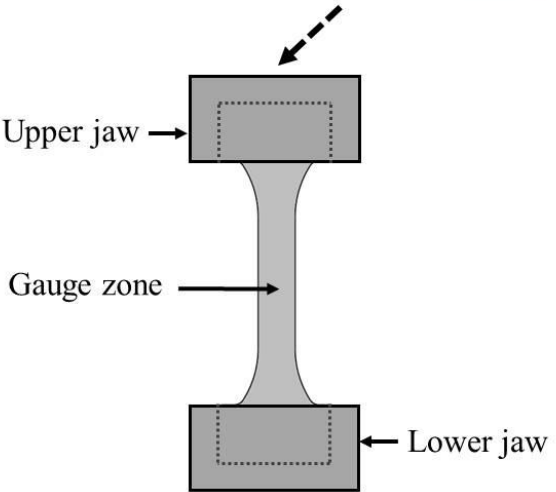

(b)

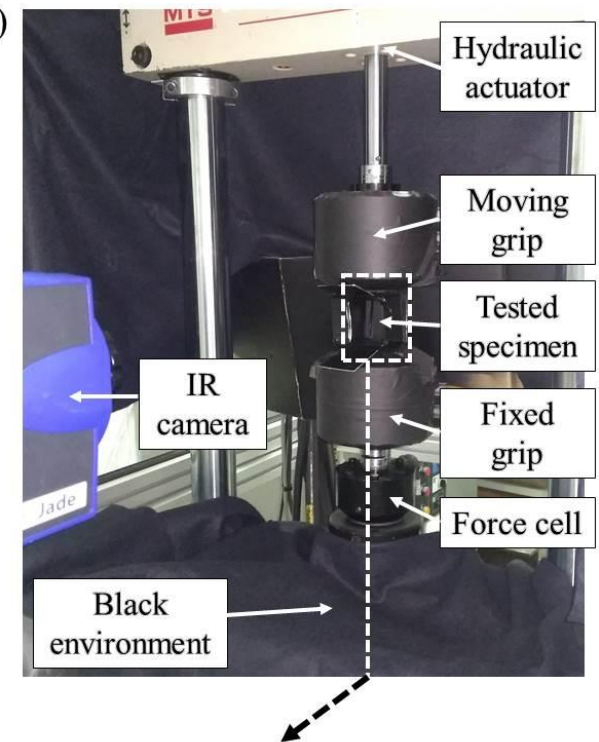

(d)

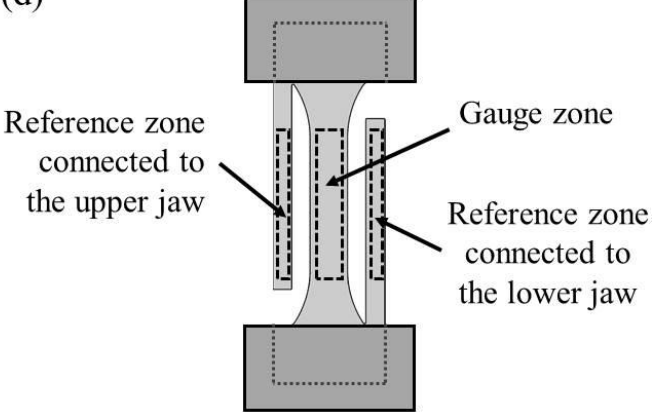

Fig. 3. (a) Experimental setup for conventional fatigue tests; (b) experimental setup for fatigue tests instrumented with IR camera; (c) schematic view of the specimen geometry in the jaws of the testing machine for conventional fatigue tests; (d) same for fatigue tests instrumented with IR camera.

The geometry of the mechanically-loaded part of the specimens was the same for both types of tests: compare Figs. 3(c) and (d). The dimensions of the gauge zone were $10 \mathrm{~mm}$ in width and $40 \mathrm{~mm}$ in length, in agreement with ISO standard 1099:2017 [35]. Specimens for the tests instrumented by IR camera featured two additional "reference" parts, as proposed by Delpueyo et al. [36]. The role of these references is to track the time variation in thermal fluctuation in the specimen's environment, and more especially in the two grips of the testing machine. In particular, it should be noted that a hydraulic actuator is in general subjected to a temperature rise due to the hydraulic fluid, which thus must be taken into account in the thermal data processing. Temperature measurements were carried out using a Cedip Jade III-MWIR camera featuring a wavelength range of 3.5-5 $\mu \mathrm{m}$, a sensor size of 
$320 \times 240$ pixels and a Noise Equivalent Temperature Difference (NETD) equal to $0.02^{\circ} \mathrm{C}$ at ambient temperature.

Table 1 sums up the setup parameters. The loading frequency $f_{\mathrm{L}}$ was equal to $66 \mathrm{~Hz}$ and $30 \mathrm{~Hz}$ for conventional tests and tests instrumented by IR camera, respectively. These choices resulted from practical constraints. The former value enabled us to reduce the test duration. The latter value was determined after preliminary tests (not presented here) showing that self-heating could be captured by the IR camera using specific acquisition and recording conditions. Indeed, in order to capture only the thermal effect of mechanical dissipation over the mechanical cycles, a real-time averaging over 30 cycles was performed from a raw acquisition frequency $f_{\mathrm{A}}$ of the IR camera set to $100 \mathrm{~Hz}$. Thus the thermal recording frequency $f_{\mathrm{R}}$ was equal to $1 \mathrm{~Hz}$. This approach enabled us to remove the influence of the thermoelastic effect and to capture only the influence of mechanical dissipation associated with fatigue damage [36]. 


\begin{tabular}{|c|c|c|c|}
\hline & Conventional fatigue tests & \multicolumn{2}{|c|}{ Fatigue tests instrumented with IR camera } \\
\hline Actuator type & Electromagnetic & Hydraulic & $=$ \\
\hline Loading frequency $f_{\mathrm{L}}$ & $66 \mathrm{~Hz}$ & $30 \mathrm{~Hz}$ & $=$ \\
\hline Loading ratio $R$ & 0.1 & $=$ & $=$ \\
\hline Type of cyclic loading & $\begin{array}{l}\text { Constant maximum stress } \\
\text { until failure }\end{array}$ & \multicolumn{2}{|c|}{$\begin{array}{l}\text { Sequences of } 5 \text { min with increasing maximum } \\
\text { stress and 5-min waiting time between sequences }\end{array}$} \\
\hline Step $\Delta \sigma_{\mathrm{a}}$ of amplitude stress & $\mathrm{n} / \mathrm{a}$ & $36 \mathrm{MPa}$ & $18 \mathrm{MPa}$ \\
\hline Number of specimens tested & 28 & 12 & 2 \\
\hline Thermal acquisition frequency $f_{\mathrm{A}}$ & $\mathrm{n} / \mathrm{a}$ & $100 \mathrm{~Hz}$ & $=$ \\
\hline Thermal recording frequency $f_{\mathrm{R}}$ & $\mathrm{n} / \mathrm{a}$ & \multicolumn{2}{|c|}{$1 \mathrm{~Hz}$ (real-time averaging over 30 cycles) } \\
\hline Objective & $\begin{array}{l}\text { S-N curve and } \\
\text { fractographs by SEM }\end{array}$ & $\begin{array}{l}\text { Repeatability study } \\
\text { of mechanical } \\
\text { dissipation behavior }\end{array}$ & $\begin{array}{l}\text { Continuation of the } \\
\text { repeatability study, with } \\
\text { better stress resolution }\end{array}$ \\
\hline
\end{tabular}

Table 1. Setup parameters.

The stress ratio $R$ was set to 0.1 for all the tests performed during the study. 28 specimens were used to construct the S-N curve. Various stress amplitude values $\sigma_{\mathrm{a}}$ were applied until specimen failure with a limit of $10^{7}$ cycles: see Fig. 4(a). 14 other specimens were used for the fatigue tests instrumented by IR camera. For these tests, loading sequences of five minutes (i.e. 9000 mechanical cycles) were applied with progressively increasing stress amplitude $\sigma_{\mathrm{a}}$, until failure: see Fig. 4(b). A five-minute waiting time was imposed between two successive sequences so that the specimen could return to thermal equilibrium before starting a new loading sequence. Twelve specimens were tested with a stress amplitude $\Delta \sigma_{\mathrm{a}}$ step equal to $36 \mathrm{MPa}$ (i.e. a step $\Delta \sigma_{\max }$ of maximum stress equal to 80 $\mathrm{MPa})$, whereas two specimens were tested with $\Delta \sigma_{\mathrm{a}}=18 \mathrm{MPa}\left(\right.$ i.e. $\left.\Delta \sigma_{\max }=40 \mathrm{MPa}\right)$ :

- by construction, the $18 \mathrm{MPa}$ loading step provides a better resolution in stress than the $36 \mathrm{MPa}$ loading step. However, specimen failure is expected at lower loading levels because of more accumulated fatigue damage (roughly twice as much for the same maximum stress reached);

- the $36 \mathrm{MPa}$ loading step combines two advantages: tests are shorter, while reaching higher stress levels than with the $18 \mathrm{MPa}$ loading step. 


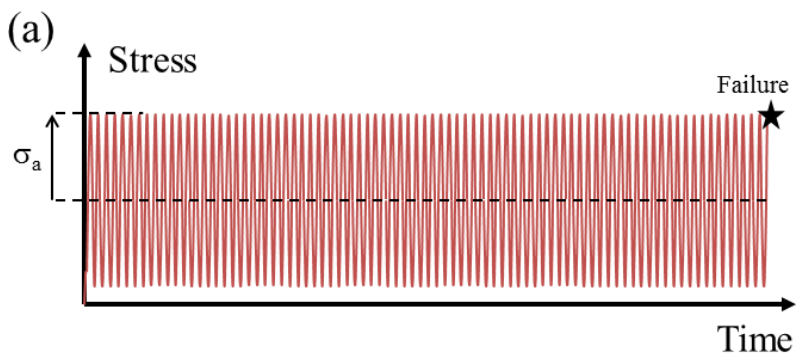

(b)

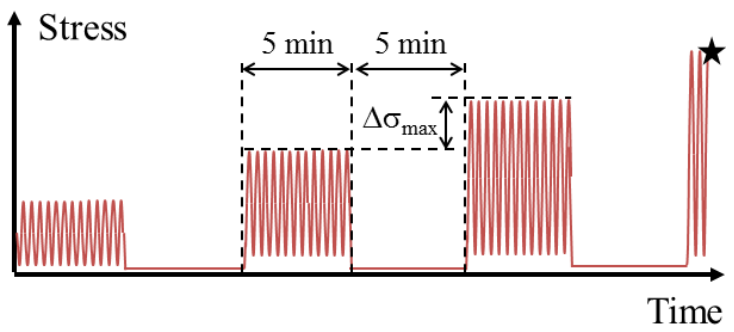

Fig. 4. Schematic view of the mechanical loading: (a) for conventional fatigue tests; (b) for fatigue tests instrumented with IR camera.

The total duration of the conventional fatigue tests to build the S-N curve was about two months. The total duration of the test campaign instrumented by IR camera was about two weeks, including preparation and preliminary tests. Fatigue characterization by IR camera is known to be rapid while using a small number of specimens [20-22]. It should be recalled that the objective here was to perform a repeatability study with statistical data analysis and to propose a model for mechanical dissipation behavior (see Sections 5 and 6).

\section{Results of conventional fatigue tests}

Fig. 5(a) shows the S-N data plot of the 28 specimens subjected to conventional fatigue tests, using the stress amplitude $\sigma_{\mathrm{a}}$ for the y-axis, as is usual for this type of representation. It can be observed that the dispersion of the data is high, which makes the determination of the fatigue limit questionable. However, dispersion appears to be lower when splitting the data between specimens from printing zones L and R, as defined in Fig. 2(a). This could be explained by an effect of the direction of powder 
deposition or gas flow [32, 33]. Specimens from zone $\mathrm{R}$ appear to have a longer fatigue life. Complementary information was obtained from fractography analysis by Scanning Electron Microscopy (SEM) using a Hirox SH-4000M microscope: see Fig. 6 showing four different types of crack initiation sites. As expected and already shown, for instance in Refs [6, 9-11], crack initiation sites were located at porosities originating from a lack of fusion during the manufacturing process. Moreover, most of the critical porosities were located at or near the surface of the specimen: see Figs. 6(a) and (b) respectively. An internal porosity (i.e. a porosity whose shortest distance from the specimen's boundary is greater than its equivalent diameter) such as in Fig. 6(c) led to the failure of only one specimen. A widespread defect at the surface, as in Fig. 6(d), was observed for three specimens. This latter type of defect is typical of the propagation of an initial melting defect through several powder layers during manufacturing. The areas of the critical porosities were measured in two dimensions from the SEM images. The order of magnitude for the main critical porosities was found to be between $1 \mathrm{E}+2$ and $1 \mathrm{E}+3 \mu \mathrm{m}^{2}$. Fig. $5(\mathrm{~b})$ displays the $\mathrm{S}-\mathrm{N}$ data, including information about the critical porosities' areas and positions relative to the specimen's boundary. In general, specimens from zone $\mathrm{R}$ of the building plate featured smaller porosities than those manufactured in zone $\mathrm{L}$, corroborating their longer fatigue lives. It should also be noted that the four unrepresentative defects, namely the internal porosity (arrow A in Figs 5(a) and (b)) and the widespread defects (arrows B, C and $\mathrm{D}$, corresponding to an area of more than $1 \mathrm{E}+4 \mu \mathrm{m}^{2}$ ) led to fatigue responses which differ from the rest of the specimens. They have particularly good and particularly bad fatigue behaviors respectively. These four specimens shall thus not be taken in account for fatigue limit identification. 

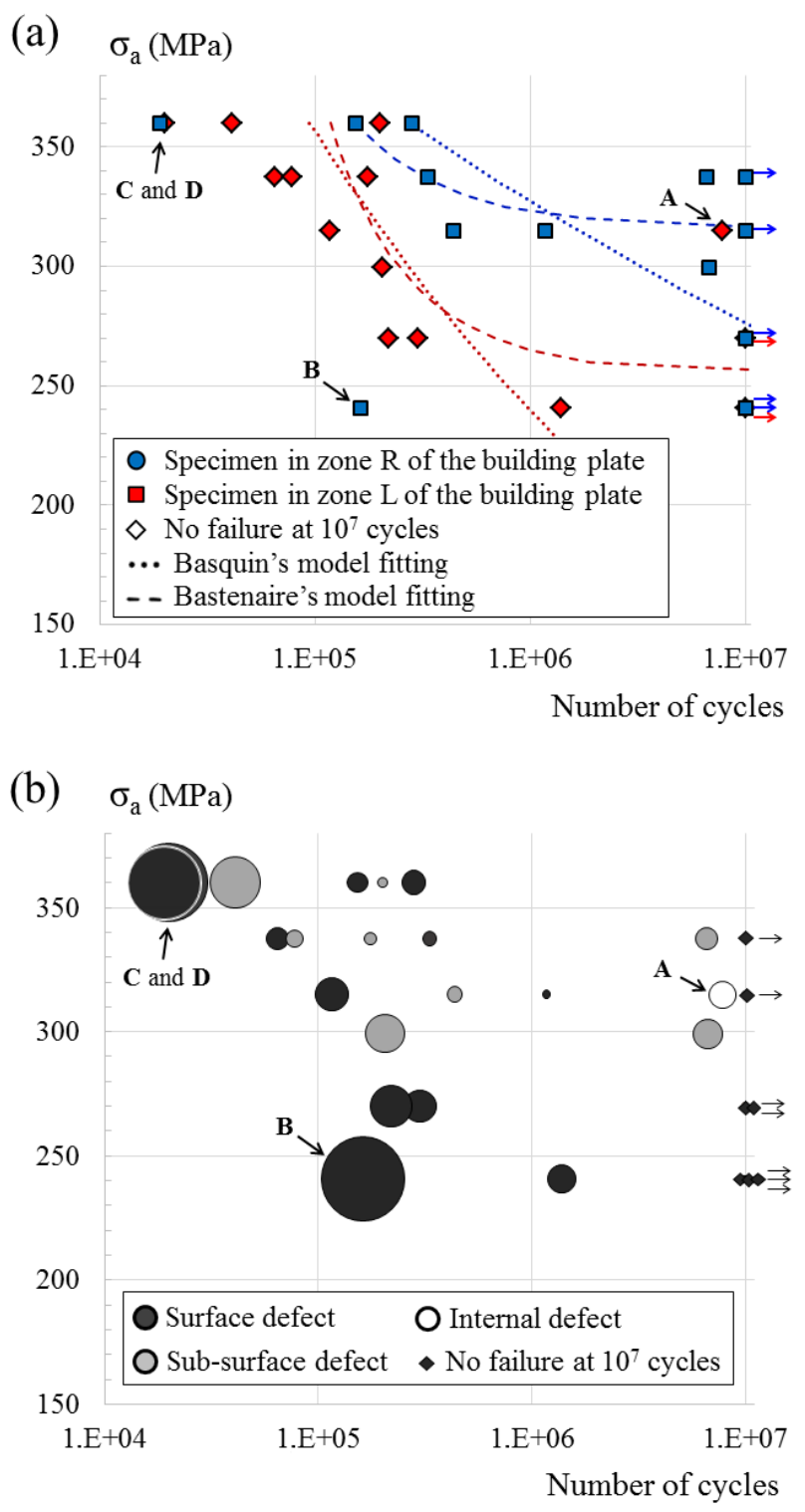

Fig. 5. S-N data plots obtained from the conventional fatigue tests: (a) comparison between specimens placed in the $\mathrm{L}$ and $\mathrm{R}$ zones of the building plate during manufacturing; (b) comparison between the types of defects observed in the facture zone of the broken specimens. The diameter of the circles is proportional to the area of the defect. 


\section{(a)}

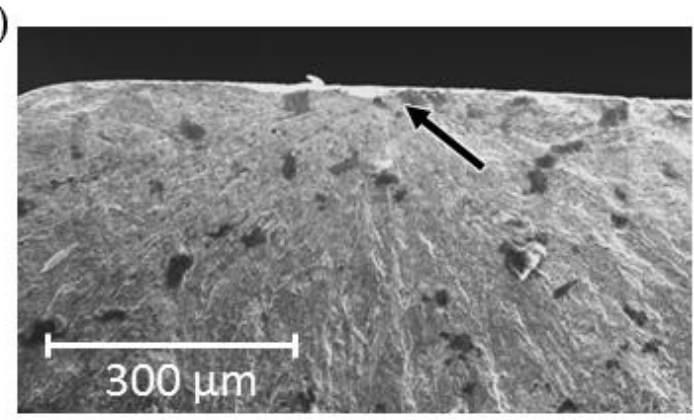

(b)

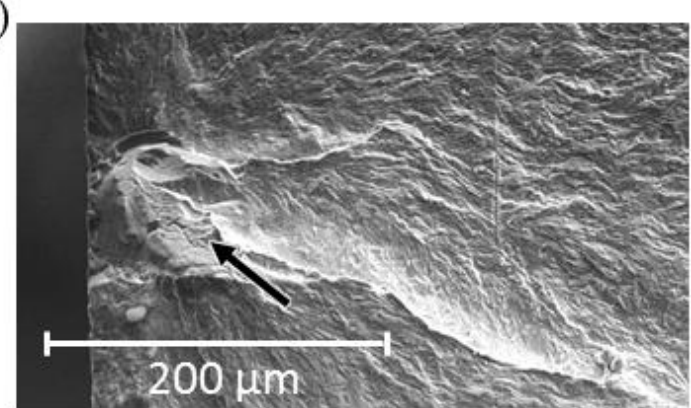

(c)

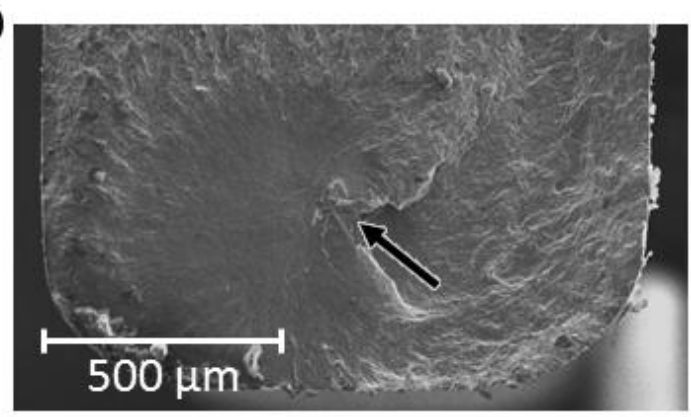

(d)

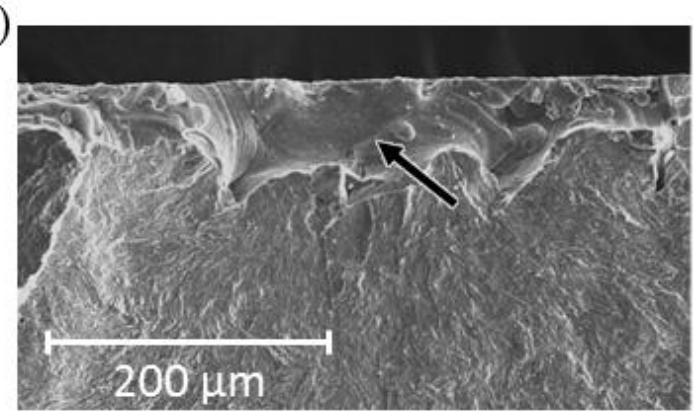

Fig. 6. SEM micrographs of four representative fracture initiation sites after conventional fatigue tests: (a) small surface defect; (b) medium sub-surface defect; (c) small internal defect; (d) large surface defect.

For further analysis, Basquin's model was first coupled with the Fisher-Snedecor test [37] for validation purposes and in order to check the dispersion of the $\mathrm{S}-\mathrm{N}$ data. If the test is rejected, another model should be used, or the effective control of the manufacturing process must be questioned. The test consists in comparing the ratio between the variance explained by Basquin's model and the residual variance with respect to a threshold $\gamma$. In the present paper, this test is used to validate or not 
the existence of two "distinct" populations depending on their locations on the building plate (specimens $\mathrm{L}$ and $\mathrm{R}$ ). Table 2 provides the threshold $\gamma$ enabling the validation of the Fisher-Snedecor test for the different populations, a maximum value of $10 \%$ usually being considered as validating the model and the good control of the manufacturing process producing the set of specimens tested [38]. It appears that the test is validated when considering specimens $\mathrm{L}$ only $(\gamma=5 \%)$, which is not the case when considering specimens $\mathrm{L}+\mathrm{R}(\gamma=17 \%)$ and specimens $\mathrm{R}$ only $(\gamma=14 \%)$. The coefficient of variation $\mathrm{CV}$ of the differences between the experimental data and the model is also indicated in the table for the three sets of specimens. It is confirmed that specimens $\mathrm{L}+\mathrm{R}$ do not represent a "single" manufacturing process $(\mathrm{CV}=32.8 \%)$. Specimens $\mathrm{L}$ and $\mathrm{R}$ can be considered as representing distinct manufacturing processes $(\mathrm{CV}=10.4 \%$ and $9.6 \%$ respectively). Although Basquin's model is relevant for the description of the linear part of the Wöhler curves, the Bastenaire model fits the data much more accurately, taking into account the asymptote of the Wöhler curve. This latter model was therefore used to fit the data more accurately and to estimate the fatigue limit at $10^{7}$ cycles for the $\mathrm{L}$ and R specimens: see Table 3. The values are low compared to the ultimate tensile strength of the material, which was expected due to the absence of HIP treatment. The result obtained for the L specimens is compared in Section 5 to the results of fatigue tests instrumented by IR camera. Before that, the next section recalls the background concerning the data processing used to extract mechanical dissipation due to fatigue damage.

\begin{tabular}{lll}
\hline & $\begin{array}{l}\text { Threshold } \gamma \text { allowing validation } \\
\text { of the Fisher-Snedecor test }\end{array}$ & $\begin{array}{l}\text { Coefficient of variation CV of the differences } \\
\text { between experimental data and model }\end{array}$ \\
\hline Specimens L+R & $17 \%$ & $32.8 \%$ \\
Specimens L & $5 \%$ & $10.4 \%$ \\
Specimens R & $14 \%$ & $9.6 \%$ \\
\hline
\end{tabular}

Table 2. Analysis of the fatigue life $N$ from Basquin's model. 


\begin{tabular}{ll}
\hline & Fatigue limit \\
\hline Specimens L & $255 \mathrm{MPa}$ \\
Specimens R & $316 \mathrm{MPa}$
\end{tabular}

Table 3. Fatigue limits $\sigma_{\mathrm{D}}$ estimated using the Bastenaire model from conventional fatigue tests for $50 \%$ failure probability.

\section{Background to mechanical dissipation identification}

This section presents the data processing that was used to calculate the mechanical dissipation associated with fatigue damage from the temperatures provided by the IR camera, see Fig. 7(a). This processing was performed using the so-called "heat source reconstruction" technique, which is based on the heat diffusion equation. By heat source, we mean the heat power density (in $\mathrm{W} / \mathrm{m}^{3}$ ) produced or absorbed by the material itself due to a change in its mechanical state. This quantity is composed of two parts [39]:

- one part is associated with thermomechanical couplings, which are limited to thermoelastic coupling in most materials. In the case of isotropic materials, it is expressed by

$$
s_{\text {the }}=-3 \alpha T \frac{\mathrm{d} \sigma_{\mathrm{h}}}{\mathrm{d} t}
$$

where $\alpha$ is the coefficient of thermal expansion, $T$ the temperature expressed in $\mathrm{K}$ and $\mathrm{d} \sigma_{\mathrm{h}} / \mathrm{d} t$ the time derivative of the hydrostatic stress $\sigma_{\mathrm{h}}$ [40]. Loading and unloading in tension are thus accompanied by heat absorption (temperature decrease) and release (temperature increase), respectively. It is worth noting that the total heat due to thermoelastic coupling is null over a thermodynamic cycle;

- the other part is the mechanical dissipation (also named intrinsic dissipation), a calorific quantity which is often denoted $d_{1}$ to be distinguished from thermal dissipation $d_{2}$ in the 
Clausius-Duhem inequality $d_{1}+d_{2} \geq 0$. Mechanical dissipation is related to irreversibility such as plasticity, viscosity, or fatigue damage as in the present study. Mechanical dissipation is always positive: $d_{1} \geq 0$.

The reader can refer to Ref. [39] for the different formulations of the heat diffusion equation to be used for heat source calculation from experimental thermal data obtained by IR thermography. In particular, a so-called zero-dimensional (OD) version can be applied when heat sources are considered to be homogeneous in the specimen, in particular when the strain fields are homogeneous at the considered spatial resolution. This consists in using the temperature changes averaged over the gauge zone of the specimen. See Refs $[36,41]$ for the details of this approach, which is both simple and powerful. It should be noted that the OD approach requires the homogeneity of the heat source fields, not the temperature fields. Moreover, spatial averaging strongly improves the resolution of the thermal measurement, enabling us to decrease the raw NEDT to a few thousandths of one degree; see figure 7 of Ref. [36] for an example of such image processing. Equation (2) shows the relation between the (homogeneous) heat source $s(t)$ and the average temperature change $\theta_{0 \mathrm{D}}(t)$ :

$$
s=\rho C\left(\frac{\mathrm{d} \theta_{0 \mathrm{D}}}{\mathrm{d} t}+\frac{\theta_{0 \mathrm{D}}}{\tau}\right)
$$

where $\rho$ is the material density, $C$ the specific heat and $\tau$ a time constant characterizing the global heat exchanges with the environment of the specimen. The value of $\tau$ can initially be measured by considering a natural return to ambient temperature $(s=0)$, the specimen being placed in the jaws of the testing machine. Indeed, the solution to Eq. (2) for $s=0$ is an exponential function whose decay constant is $\tau$. 
(a)
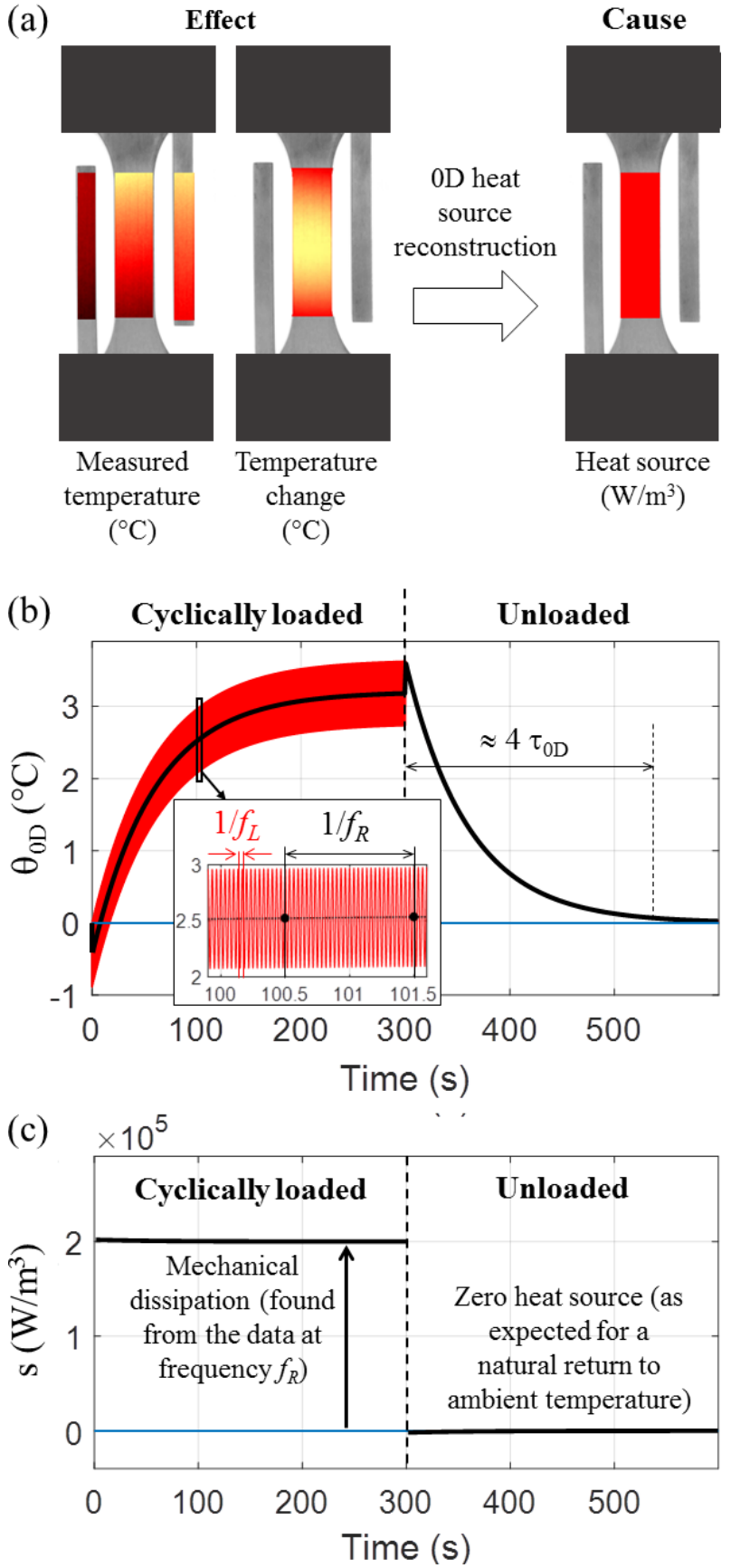

Fig. 7. Data processing approach for the fatigue tests instrumented by IR camera: (a) illustration of the OD approach; (b) time variation of the spatially-averaged temperature change under cyclic mechanical loading for $300 \mathrm{~s}$, followed by a natural return to ambient temperature; (c) corresponding time variation of the heat source calculated from the data averaged in time over an integer number of mechanical cycles. The input thermal data in this figure was provided by a numerical model.

A numerical simulation of a fatigue test instrumented by IR camera is now presented to illustrate the procedure to extract the mechanical dissipation $d_{1}$ from the thermal data. The following 
thermophysical properties of steels were considered: $\rho=7800 \mathrm{~kg} / \mathrm{m}^{3}, C=480 \mathrm{~J} /(\mathrm{kg} . \mathrm{K})$ and $\alpha=1210^{-6}$ $\mathrm{K}^{-1}$. Sinusoidal uniaxial loading at frequency $f_{\mathrm{L}}=30 \mathrm{~Hz}$ was considered, similarly to the experiments, with a stress amplitude $\sigma_{\mathrm{a}}$ of $414 \mathrm{MPa}$. From Eq. (1), it can be calculated that the thermoelastic heat source $s_{\text {the }}$ oscillates between about $\pm 2.80 \times 10^{8} \mathrm{~W} / \mathrm{m}^{3}$. For the present numerical illustration, the mechanical dissipation $d_{1}$ was assumed to be a constant: $2 \times 10^{5} \mathrm{~W} / \mathrm{m}^{3}$, i.e. a small value compared to the amplitude of the thermoelastic heat source observed in real experimental cases. The time constant $\tau$ was set to $60 \mathrm{~s}$, which is the value identified from experimental natural cooling. Based on this input data, synthetic temperature changes $\theta$ were created from Eq. (2) using an implicit Euler scheme: see the red curve in Fig. 7(b). Then the obtained thermal signal was averaged over time every 30 mechanical cycles, similarly to the experimental protocol (recording frequency $f_{\mathrm{R}}=1 \mathrm{~Hz}$, see Section 2.2): see the black curve in Fig. 7(b). Temperature oscillation at $30 \mathrm{~Hz}$ is thus "removed" by this procedure. However, by construction, the thermoelastic effect remains visible at the beginning and the end of the cyclic loading: see the "immediate" temperature decrease and increase, respectively, in the black curve. Finally, heat sources were calculated from Eq. (2) using the data at recording frequency $f_{\mathrm{R}}$ : see Fig. $7(\mathrm{c})$. It can be observed that data processing enables us to successfully obtain directly the mechanical dissipation $d_{1}$ during the cyclic loading stage (the strong thermoelastic coupling is completely cancelled). A zero value is also obtained in the natural cooling stage, as expected. This processing is applied to the experimental data in the next session.

\section{Results of the fatigue tests instrumented by IR camera}

Results of fatigue tests are now presented in terms of thermal and calorific response (Section 5.1) and a model is proposed to describe mechanical dissipation behavior (Section 5.2). All the 14 tested specimens were manufactured with the same strategy as that used for conventional fatigue tests. We selected them all from printing zone "L" to perform a repeatability study with statistical analysis. 
Furthermore, this choice enables us to be in the worst case in terms of fatigue performance: $\left(\sigma_{\mathrm{D}}\right)_{\text {Bastenaire }}=255 \mathrm{MPa}$, see Table 3.

\subsection{Experimental results}

Fig. 8(a) shows a typical temperature progression associated with the loading procedure in Fig. 4(b). Let us recall that the oscillating effect of the thermoelastic coupling was removed thanks to real-time averaging (see Section 2.2). It can be observed that each loading sequence starts with an immediate decrease (see arrows A) and finishes with an immediate increase (arrows B), which are a residual effect of the thermoelastic coupling, as explained in Section 4 and illustrated in Fig. 7(b). A return to ambient temperature is observed for each five-minute waiting time imposed between two successive sequences (see arrows C). Heat sources close to zero are logically detected during these waiting times: see arrows E in Fig. 8(b). A temperature rise is observed along each loading sequence, with stabilization after a few minutes (see arrows D). Constant mechanical dissipation is identified during these loading sequences: see arrows F. However, it can be noted that mechanical dissipation slightly decreases for the highest loading levels: see arrows G. This could be explained by a decrease in microplasticity rate over successive cycles. An average value is extracted for the analysis in Section 5. Finally, let us note that failure occurred shortly after the beginning of the last loading sequence. It was possible to extract a mechanical dissipation value for this last loading sequence: see star H in Fig. 8(b). 
(a)

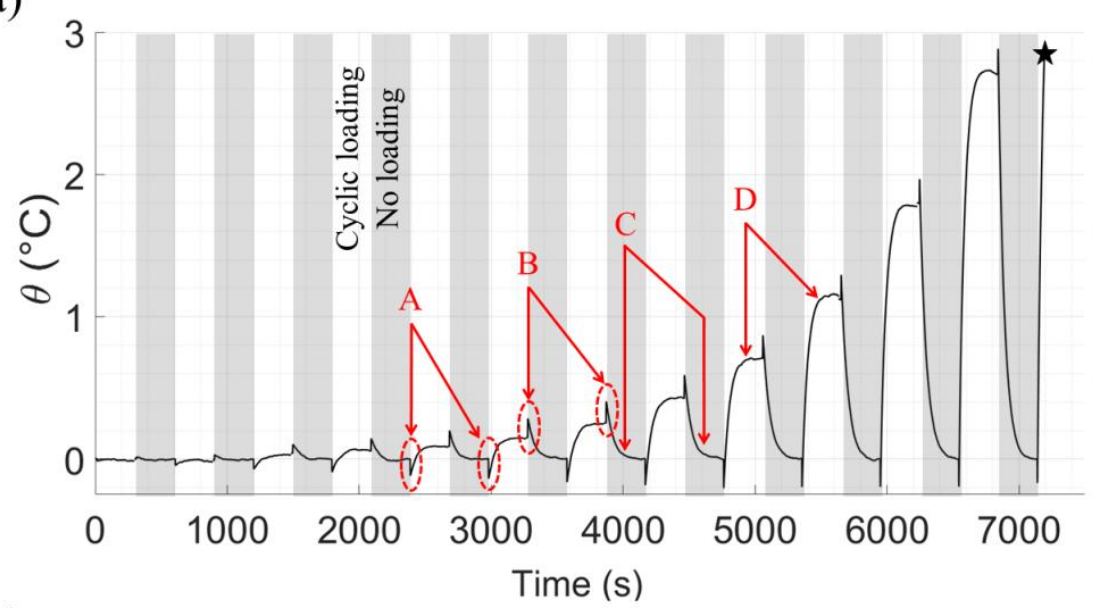

(b)

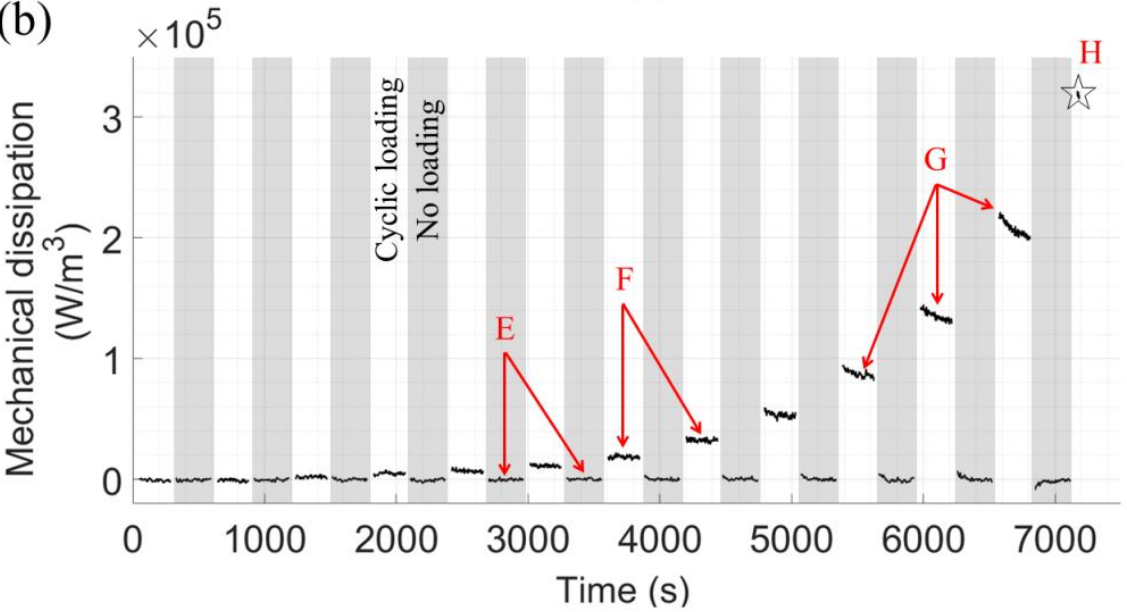

Fig. 8. Typical result of fatigue test instrumented with IR camera, for specimen \#9: (a) averaged temperature change as a function of time; (b) mechanical dissipation as a function of time.

Fig. 9(a) shows the mechanical dissipation vs. stress amplitude plot for the 14 specimens tested. Two regimes can be identified, defined as primary and secondary in the following as proposed by Munier $e t$ al. in Ref. [25]. At low stress, i.e. below the fatigue limit, the mechanical dissipation is low and slightly increases. This response can be attributed to irreversible microstructural mechanisms such as intragranular misorientation [26] independent from fatigue damage, or maybe related to VHC fatigue. At higher stresses, i.e. above the fatigue limit, fatigue damage strongly increases with the loading level. These two regimes are more clearly evidenced using a log-log scale plot: see Fig. 9(b). However, the transition, i.e. the fatigue limit $\sigma_{\mathrm{D}}$, is difficult to estimate. Note that the signal-to-noise ratio is low at low stress amplitudes and leads to some (small) negative values at the beginning of the curves in Fig. 9(a). This is why the corresponding points are not displayed in logarithmic scale in Fig. 
9(b). The objective now is to derive a fatigue limit value $\sigma_{\mathrm{D}}$ from the experimental calorimetric data, in other words to find an "inflection" point between the two regimes in Figs. 9(a) or (b). The tangent methods, introduced by Luong [20, 21] (using two tangents) and La Rosa and Risitano [22] (using one tangent), are commonly used as a criterion for estimating the fatigue limit from thermal data. These methods, also named graphic methods [42] or qualified as deterministic approaches [24, 25], assume that the thermal response features two linear tendencies: one when the stress amplitude tends to zero and one when the stress amplitude tends to the ultimate strength. The intersection of the two asymptotes is considered as defining the fatigue limit of the material. As pointed out by Huang et al. [42], the tangent methods are rapid, and provide a correct order of magnitude of the material's fatigue limit, but contain man-made uncertainties. No strict protocol had been defined until the work of Huang et al. [42] who first proposed to standardize the methodology to identify the material's fatigue limit, testing several methodologies from temperature data available in the literature and analyzing in detail the relevance of each methodology. The present study is inspired by this work, considering calorific data (mechanical dissipation) rather than thermal data. A model for this mechanical dissipation is developed in the next section and will then be used for statistical analysis from simulations (Section $6)$. 

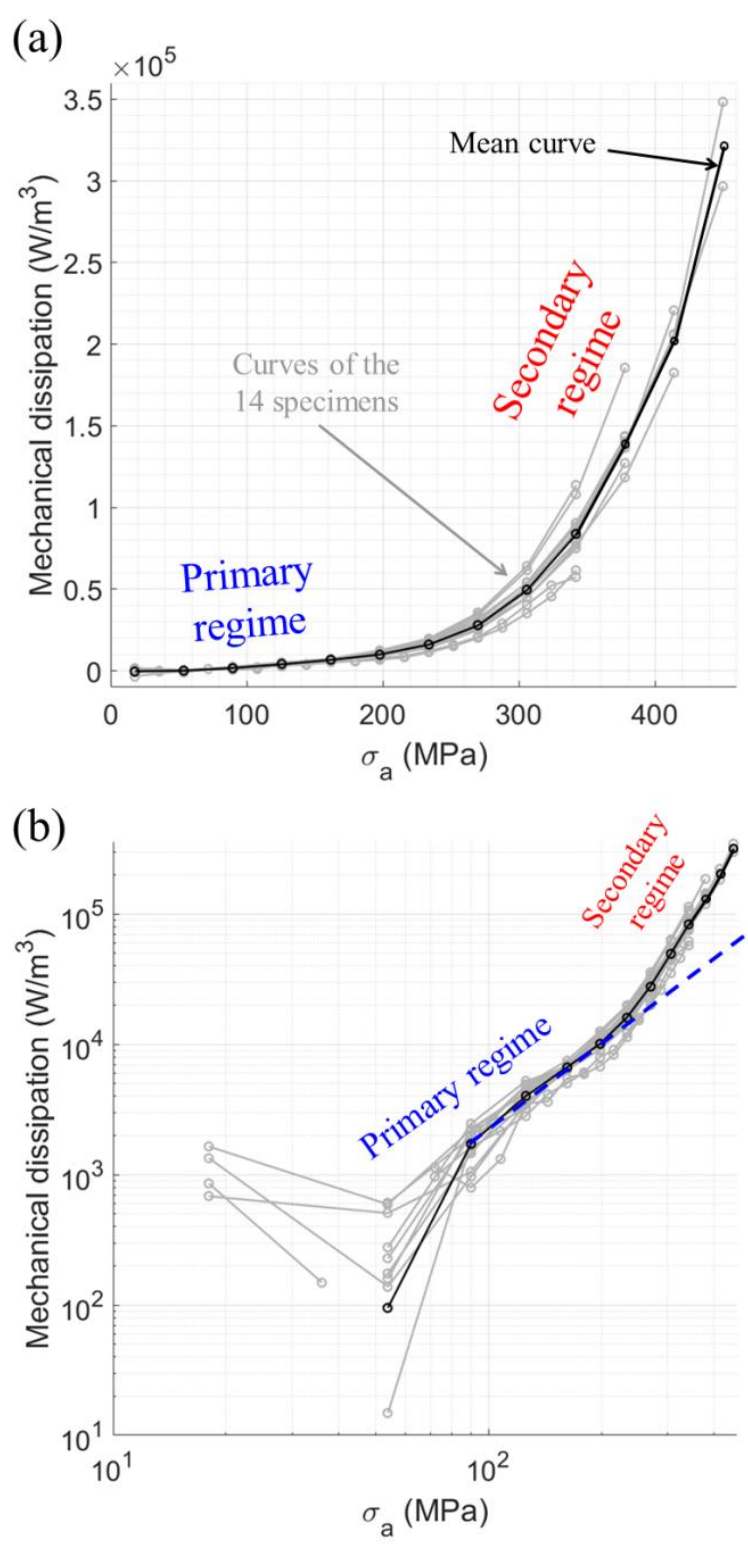

Fig. 9. (a) Mechanical dissipation $v s$. stress amplitude for the 14 tested specimens;

(b) same in log-log plot.

\subsection{Proposed model}

Several works have evidenced the presence of two thermal regimes involving two dissipative mechanisms. Munier et al. explained the first regime under low-amplitude cyclic loadings as the consequence of elasto-plastic behavior, which can be modeled by a quadratic function of the stress amplitude [25, 26]. In the case of maraging steel, it was shown in Ref. [43] that the primary calorific regime is also well described by a quadratic tendency and the secondary by an exponential tendency. 
We thus propose the following mathematical model to describe the mechanical dissipation behavior $d_{1}$ as a function of the stress amplitude $\sigma_{\mathrm{a}}$, illustrated by Fig. 10:

$$
d_{1}\left(\sigma_{\mathrm{a}}\right)=f_{1}\left(\sigma_{\mathrm{a}}\right)+f_{2}\left(\sigma_{\mathrm{a}}\right)
$$

with

$$
\begin{aligned}
& f_{1}\left(\sigma_{\mathrm{a}}\right)=a \times \sigma_{\mathrm{a}}{ }^{2} \\
& f_{2}\left(\sigma_{\mathrm{a}}\right)=\left\{\begin{array}{c}
0, \text { if } \sigma_{\mathrm{a}} \leq h \\
b \times\left(\mathrm{e}^{c \times \sigma} \mathrm{a}-\mathrm{e}^{c \times h}\right), \text { if } \sigma_{\mathrm{a}} \geq h
\end{array}\right.
\end{aligned}
$$

where $a$ (in W. $\left.{ }^{-3} \cdot \mathrm{MPa}^{-2}\right), b$ (in W. $\mathrm{m}^{-3}$ ) and $c\left(\right.$ in $\mathrm{MPa}^{-1}$ ) are the shape factors of the curve and $h$ (in MPa) the stress amplitude corresponding to the transition between the two regimes. Function $f_{1}$ describes the mechanical dissipation in the primary regime, and function $f_{2}$ corresponds to the part of mechanical dissipation which is due to fatigue damage in the secondary regime. Equality $f_{2}\left(\sigma_{\mathrm{a}} \leq h\right)=$ 0 is justified by the fact that, by construction, failure is not observed below the fatigue limit. The fact that $f_{1}\left(\sigma_{\mathrm{a}} \geq h\right)$ retains the quadratic tendency is justified by the fact that the irreversible microstructural mechanisms independent from fatigue damage have no reason to vanish in the secondary regime. 


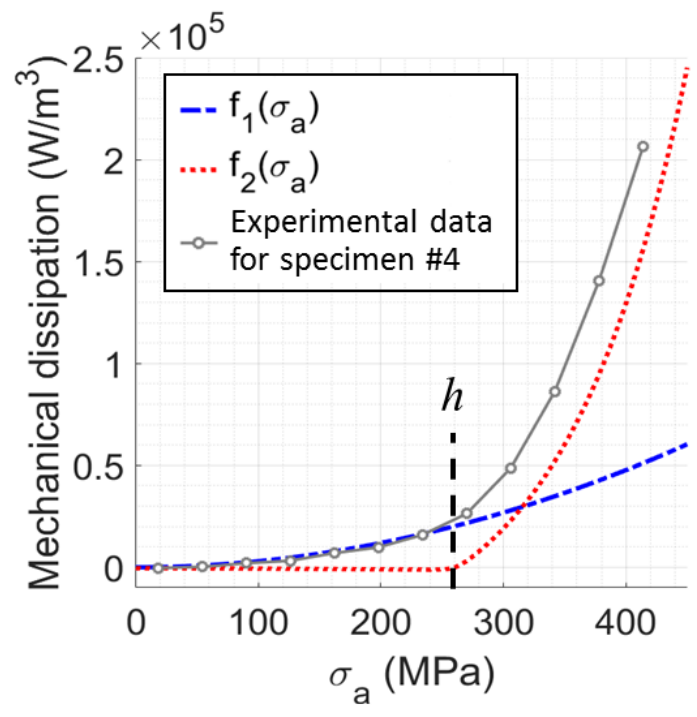

Fig. 10. Illustration of the model fitted to the Specimen \#4 data set: functions $f_{1}$ and $f_{2}$ describe the mechanical dissipation behavior as a function of the stress amplitude $\sigma_{\mathrm{a}}$.

\subsection{Proposed criteria for fatigue limit identification}

This section presents several criteria for fatigue limit estimation from the calorific data. Let us denote $n$ the number of stress amplitudes $\left\{\sigma_{\mathrm{a}_{-} i}\right\}_{i=1, \ldots, n}$ applied to the specimens. Let us denote $d_{1 \_i}$ the mechanical dissipation value at loading level $\sigma_{\mathrm{a}_{-} i}$, for a given specimen or averaged over a certain number of specimens (see next section for statistical considerations). Finally, let us denote $\sigma_{\mathrm{DB}_{-} j}$ the fatigue limit estimated with Criterion $j$. Four criteria were considered in the present study, the first two being derived from the model presented in the previous section:

- Criterion 1 - Experimental input data $\left(\sigma_{\mathrm{a}_{\_} i}, d_{1_{-}}\right)_{i=1, \ldots, n}$ are fitted from the expressions defined by Eqs. (3-5). Parameters $a, b, c$ and $h$ can be left free in the optimization. However, for the identification of the statistical variability of these parameters, the fact that $b$ and $c$ are correlated requires that one of these two parameters be fixed. It was decided to fix the secondary-regime parameter $c$ at $0.0103 \mathrm{MPa}^{-1}$, which is the mean value of this parameter from the 14 specimens. The fatigue limit estimated by the criterion is the value of $h$ obtained by the fitting operation, i.e. $\sigma_{\mathrm{DB}_{-} 1}=h$. 
- Criterion 2 - Same as Criterion 1 but the estimated fatigue limit $\sigma_{\mathrm{DB}_{-} 2}$ is defined as the maximum of the second derivative $\mathrm{d}^{2} d_{1} / \mathrm{d} \sigma_{\mathrm{a}}{ }^{2}$ of the fitted expression. This idea is inspired by the work by Huang et al. [42], which uses the curvature. Even if its results are expected to be very close to those of criterion 1 , this second criterion is more general and could be applied to modified versions of the model in the future.

- Criterion 3 - Two subsets $\left(\sigma_{\mathrm{a}_{-} i}, d_{1 \_i}\right)_{i=1, \ldots, m}$ and $\left(\sigma_{\mathrm{a}_{-} i}, d_{1 \_i}\right)_{i=m, \ldots, n}$ are defined such that the integer $m$, whose value is between 3 and $n-2$, maximizes the product $r_{1}^{2} \times r_{2}^{2}$, where $r_{1}$ and $r_{2}$ are the correlation coefficients of the linear regression on the two subsets. The estimated fatigue limit $\sigma_{\mathrm{DB}_{-} 3}$ is then defined as the intersection between these two linear regressions. This idea is also inspired by the work by Huang et al. [42], which uses the sum of the two squared correlation coefficients instead of their product.

- Criterion 4 - A linear regression is made on the subset $\left(\sigma_{\mathrm{a}_{\_} i}, d_{1_{\_} i}\right)_{i=1, \ldots, p}$ for every integer $p=2, \ldots, n$. A set composed of the $n-1$ correlation coefficients of the linear regression is thus obtained: $\left\{r_{i}^{2}\right\}_{i=2, \ldots, n}$. The set $\left(\sigma_{\mathrm{a}_{-} i}, r_{i}\right)_{i=2, \ldots, n}$ is finally fitted with a spline curve $r\left(\sigma_{\mathrm{a}}\right)$ and the estimated fatigue limit $\sigma_{\mathrm{DB}_{-} 4}$ is defined as the maximum of the slope $\mathrm{d} r / \mathrm{d} \sigma_{\mathrm{a}}$ of the spline curve.

\subsection{Application of the model to the experimental calorimetric data}

Table 4 gives the fatigue limits obtained when applying the four criteria to each of the 14 experimental data sets (14 specimens tested). Except for the outliers indicated in italics (mainly for Criterion 4), the results are close to the fatigue limit obtained with the S-N data and Bastenaire's model (255 MPa). Criteria 1 and 2 provide almost the same mean value $\left(\sigma_{\mathrm{DB}_{-} 1}=255 \mathrm{MPa}\right.$ and $\left.\sigma_{\mathrm{DB}_{-} 2}=254 \mathrm{MPa}\right)$ and same standard deviation (9 MPa). For Criterion 3, the standard deviation (38 MPa) is in fact greatly affected by one outlier, but the mean value is acceptable $\left(\sigma_{\mathrm{DB}_{-} 3}=248 \mathrm{MPa}\right)$. Criterion 4 is by construction easily perturbed by the measurement noise (referred to as intra-specimen dispersion in the following). This drawback can be partially removed by applying the criterion to the averaged input 
data, i.e. the mechanical dissipation values averaged over all the specimens (black curve in Fig. 9(a)): a fatigue limit $\sigma_{\mathrm{DB}_{-} 4}=274 \mathrm{MPa}$ is thus obtained from this averaged input data. Actually, a good assessment is obtained from the averaged input data whatever the criterion: see the last column of Table 4. Indeed, by construction, averaging the input data over a certain number of specimens improves the measurement resolution of the quantity concerned. It should also be noted that the remarkable coincidence between the values given by criteria 1 and 2 and that given in the Bastenaire model could be fortuitous, given the different natures of the two approaches and the relatively high dispersion of the S-N data. Section 6 proposes to assess the reliability of the criteria in terms of robustness and precision with respect to the number of specimens considered for averaging the input data and the level of intra-specimen dispersion.

\begin{tabular}{|c|c|c|c|c|c|c|c|c|c|c|c|c|c|c|c|c|}
\hline & & & & & & & Spec & mens & & & & & & & Average & From \\
\hline & $\# 1$ & $\# 2$ & $\# 3$ & $\# 4$ & $\# 5$ & \#6 & $\# 7$ & \#8 & $\# 9$ & $\# 10$ & $\# 11$ & $\# 12$ & $\# 13$ & $\# 14$ & deviation) & input data \\
\hline$\sigma_{\mathrm{DB} \_1}$ & 252 & 253 & 254 & 257 & 253 & 258 & 252 & 249 & 249 & 265 & 249 & 253 & 252 & 242 & $255(9)$ & 253 \\
\hline$\sigma_{\mathrm{DB} \_2}$ & 252 & 254 & 254 & 257 & 254 & 260 & 252 & 250 & 250 & 266 & 250 & 279 & 253 & 242 & $254(9)$ & 252 \\
\hline$\sigma_{\mathrm{DB}_{-} 3}$ & 257 & 257 & 273 & 273 & 257 & 244 & 263 & 254 & 250 & 267 & 119 & 268 & 239 & 249 & 248 & 256 \\
\hline$\sigma_{\mathrm{DB} \_4}$ & 277 & 262 & 270 & 288 & 112 & 114 & 113 & 111 & 112 & 118 & 122 & 284 & 70 & 59 & 165 (84) & 274 \\
\hline
\end{tabular}

Table 4. Fatigue limits $\sigma_{\mathrm{DB}_{-} j}$ obtained from the calorimetric data using the four criteria. Values, in MPa, are provided for each specimen (with outliers indicated in italics), on average over the 14 results as well as from the averaged input data (both in bold).

\section{Statistical analysis from simulations}

The first objective of this section is to estimate the influence of the experimental noise on the precision of each criterion for fatigue limit identification. The second objective is to provide statistical arguments for the correct assessment of the fatigue limit from mechanical dissipation data in terms of 
the number of specimens to be tested. Section 6.1 first presents the methodology for input data set generation. Section 6.2 provides the statistical analysis from the generated data sets.

\subsection{Data set generation}

The simulation of input data is based on the model defined by Eqs. (1-3). In order to randomize generation, three kinds of dispersion must be implemented in the generator:

- the inter-specimen dispersions on parameters $a, b$ and $h$ were identified from the model fitted to the 14 experimental curves in Fig. 9(a). Gumbel laws are proposed to characterize the corresponding probability density functions (PDFs). Parameter values and PDFs are shown in Figs. 11(a), (b) and (c) for parameters $a, b$ and $h$ respectively. This dispersion could be due to different temperature paths during the AM process, depending on the locations within zone "L";

- the intra-specimen dispersion corresponding to the measurement noise was identified from the mechanical dissipation values measured at the low loading level tested $\left(\sigma_{\mathrm{a}}=54 \mathrm{MPa}\right)$ : see Fig. 11(d). Identification could have been done at $\sigma_{\mathrm{a}}=0 \mathrm{MPa}$ (no loading $=$ no mechanical dissipation), but a small value of $\sigma_{\mathrm{a}}$ is preferable in order to be in cyclic test configuration (testing machine running). Note that the mean value obtained for the measurement noise is very close to zero $\left(155 \mathrm{~W} / \mathrm{m}^{3}\right)$, compared for instance with the maximum value of $3.5 \times 10^{5}$ $\mathrm{W} / \mathrm{m}^{3}$ in Fig. 9(a). The intra-specimen dispersion was characterized by the standard-deviation of the Gaussian PDF identified: $360 \mathrm{~W} / \mathrm{m}^{3}$; let us say $300 \mathrm{~W} / \mathrm{m}^{3}$ as an order of magnitude for the statistical analysis in the next section;

- the integer number $n$ of stress levels $\left\{\sigma_{\mathrm{a}_{-} i}\right\}_{i=1, \ldots, n}$ with a step $\Delta \sigma_{\mathrm{a}}$ of $18 \mathrm{MPa}$ for each "numerical" specimen was considered as randomly varying with uniform PDF between 17 and 24, mimicking the fact that specimens fail at different loading levels in practice (see gray curves in Fig. 9(a)). 
(a)

Inter-specimen

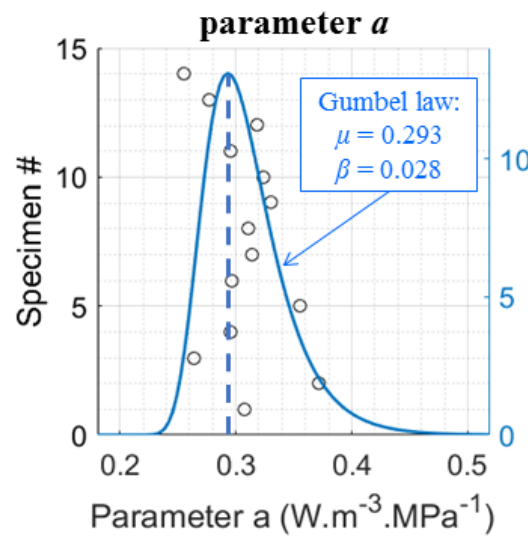

(c)

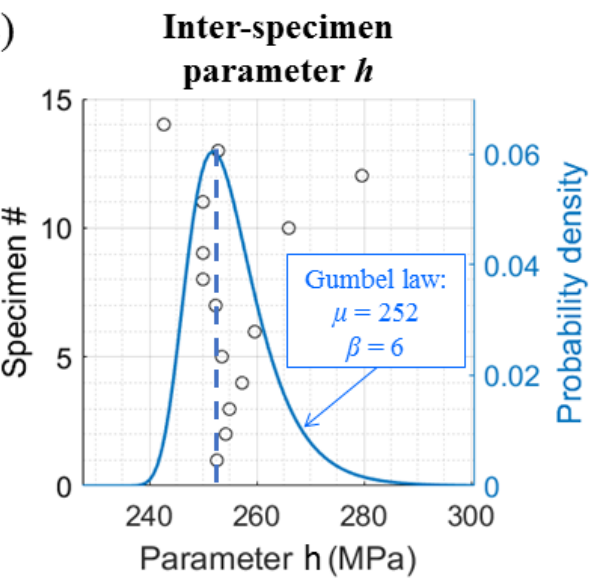

(b)

Inter-specimen

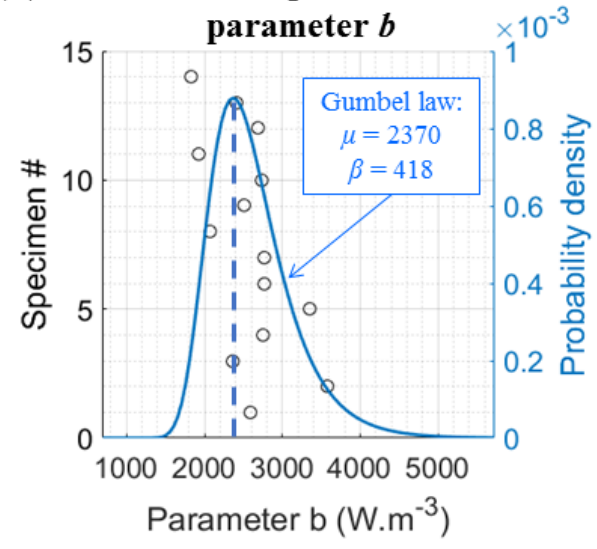

(d) Measurement noise (intra-

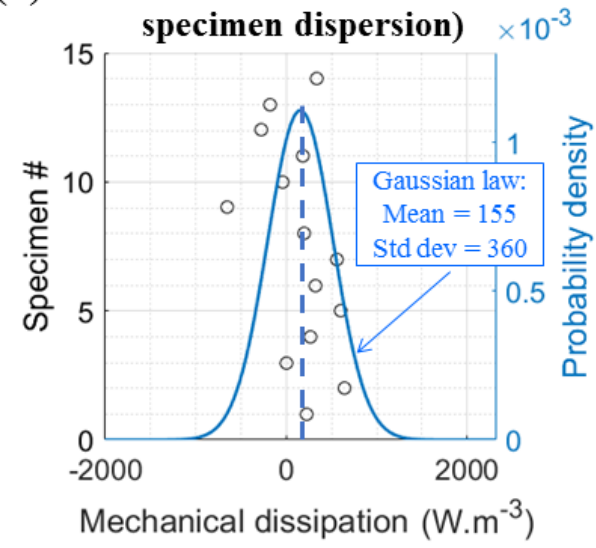

Fig. 11. Values of parameters $a, b$ and $h$ and measurement noise identified for each of the 14 specimens

(circles). Corresponding probability density functions are also plotted.

Fig. 12 shows an example of mechanical dissipation data for one numerical specimen. Generation is performed in three steps: firstly, three values are generated for parameters $a, b$ and $h$ from the Gumbel PDFs in Figs. 11(a), (b) and (c) respectively, enabling us to plot the function $d_{1}\left(\sigma_{a}\right)$, see red curve; secondly, this function is evaluated at 17 to 24 stress amplitude values $\sigma_{\mathrm{a}_{-} i}$ with a step $\Delta \sigma_{\mathrm{a}}$ of $18 \mathrm{MPa}$; finally, Gaussian noise with a standard deviation of $360 \mathrm{~W} / \mathrm{m}^{3}$, mimicking the (intra-specimen) measurement noise, is added to each value: see blue dots in the graph. Figs. 13(a) and (b) show a group of fourteen simulated data sets without and with intra-specimen dispersion respectively. We can note the good global agreement in the variability of the curves in Figs. 9(b) and 13(b). The data 
generator is used in the next section to see the influence of the number of specimens to be tested on fatigue limit identification.

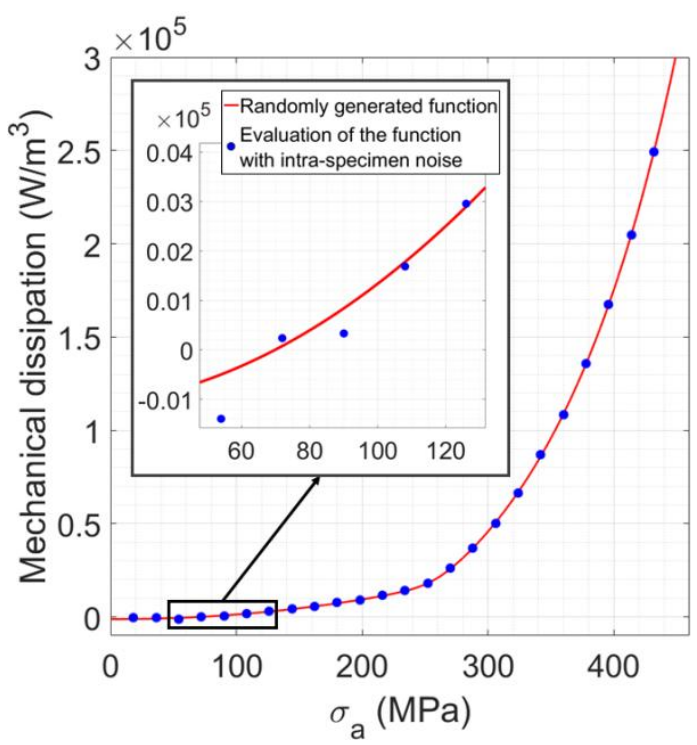

Fig. 12. Example of data set generation for one numerical specimen: mechanical dissipation as a function of stress amplitude $\sigma_{\mathrm{a}}$. 
(a)

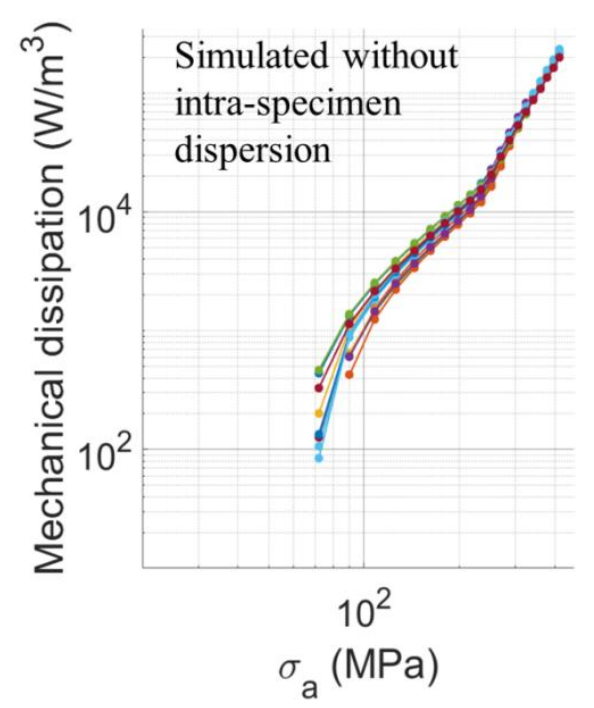

(b)

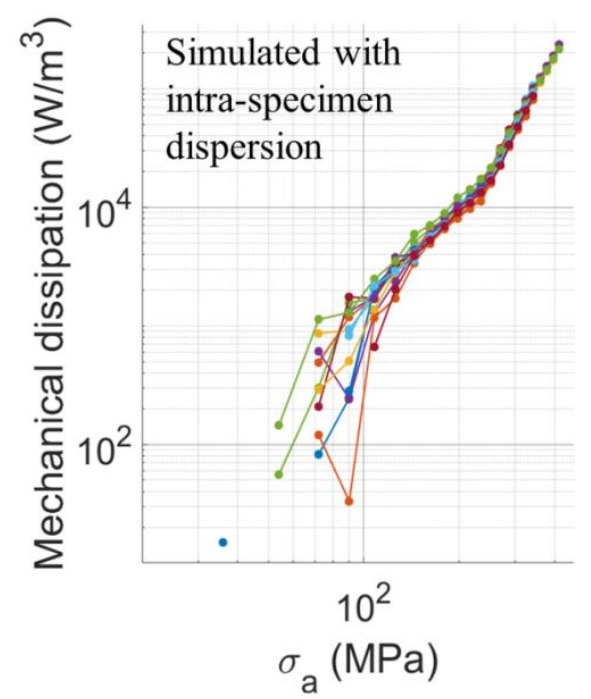

Fig. 13. Group of 14 simulated data sets (a) without and (b) with intra-specimen dispersion: mechanical dissipation as a function of stress amplitude $\sigma_{\mathrm{a}}$. Note that negative mechanical dissipation values at low loading levels (due to intra-specimen noise) are not displayed in logarithmic scale.

\subsection{Influence of the number of specimens}

The major interest of using "rapid" cyclic tests instrumented by IR camera on AM parts is to rapidly compare different manufacturing strategies in terms of fatigue performance, in order to optimize the process within a reasonable amount of time. Obtaining one set $\left(\sigma_{\mathrm{a}_{-} i}, d_{1_{-} i}\right)_{i=1, \ldots, n}$ for one specimen required less than 3 hours (not including the preparation of the test campaign and data analysis). The present section discusses the influence of the number of specimens on the precision and robustness of 
fatigue limit identification. For this purpose, twelve combinations of simulated data were defined, involving

- three levels of intra-specimen dispersion: standard deviation of $0 \mathrm{MPa}$ (no dispersion), 300 $\mathrm{W} / \mathrm{m}^{3}$ (similar to our experiments) and $600 \mathrm{~W} / \mathrm{m}^{3}$ (twice as large as our experiments). The former case enabled us to see the influence of the variability of the inter-specimen parameters only. The latter case enables us to see the impact of greater measurement noise, corresponding for example to an industrial context;

- four numbers of specimens $(1,5,15$ or 30$)$ used to average the mechanical dissipation data. As already indicated, the higher the number of specimens, the better (lower) the measurement resolution of the mechanical dissipation data. In other words, the raw intra-specimen dispersion $\left(300 \mathrm{~W} / \mathrm{m}^{3}\right.$ or $\left.600 \mathrm{~W} / \mathrm{m}^{3}\right)$ is advantageously decreased by the averaging operation. Note that inter-specimen dispersion is also smoothed by this averaging, and that several data sets are required to obtain one fatigue limit value (i.e., part of the information is lost regarding inter-specimen variability). The question can be thus formulated as follows: which value is the most robust between the average of the fatigue limits obtained over several datasets (secondlast column of Table 4) and the fatigue limit obtained using a single average dataset (last column of Table 4).

For each combination, 1000 simulations were performed, in a Monte-Carlo like approach, to extract a mean value $\sigma_{\mathrm{DB}_{-} j}$ and a standard deviation $S_{\mathrm{DB}_{-} j}$ for the fatigue limit values from the four criteria defined in Section 5.3. Simulations ran on a 16-core / 32-thread computer using Matlab software in parallel mode in about $1700 \mathrm{~s}$. Table 5 presents the results obtained. The precision of a criterion is given by the gap between the mean value $\sigma_{\mathrm{DB}_{-} j}$ and the value given by the $\mathrm{S}-\mathrm{N}$ data and Bastenaire's model $(255 \mathrm{MPa})$; its robustness is given by the standard deviation $S_{\mathrm{DB}_{-} j}$. Several remarks can be made about this table:

- for an intra-specimen dispersion equal to $0 \mathrm{~W} / \mathrm{m}^{3}$ (no measurement noise), the four criteria have quite the same good robustness. For instance, $S_{\mathrm{DB}_{-} j}$ is equal to 8-10 MPa when using 
one specimen whatever the criterion. In terms of precision, only Criterion 4 provides values which are quite far from $255 \mathrm{MPa}$ with no intra-specimen dispersion. For instance, $\sigma_{\mathrm{DB}_{-} 4}$ is around $275 \mathrm{MPa}$ whatever the number of specimens considered;

- Criterion 4 is highly penalized by the intra-specimen dispersion when using one or five specimens $\left(S_{\mathrm{DB}_{4} 4}\right.$ is equal to $86 \mathrm{MPa}$ and $24 \mathrm{MPa}$ respectively for experimental measurement noise of $300 \mathrm{~W} / \mathrm{m}^{3}$ ). Acceptable robustness is obtained when using 15 specimens for the experimental measurement noise $\left(S_{\mathrm{DB}_{-} 4}=4 \mathrm{MPa}\right)$. In all cases, the precision of this criterion is not as good as that of the three others;

- Criteria 1 to 3 are equivalent in terms of precision, whatever the number of specimens and intra-specimen noise considered: the fatigue limit is in the range 254-261 MPa. The robustness of Criterion 3 is good $\left(S_{\mathrm{DB}_{-} 3}\right.$ in the range $\left.8-10 \mathrm{MPa}\right)$, but slightly worse than that of Criteria 1 and $2\left(S_{\mathrm{DB}_{-} 1}\right.$ and $S_{\mathrm{DB}_{-} 2}$ in the range $\left.2-8 \mathrm{MPa}\right)$.

In conclusion, we propose to use Criterion 1 for fatigue limit identification in the next section. Moreover, the most relevant method is to apply it to each data set (i.e. to each specimen) to obtain one fatigue limit value per data set (i.e. per specimen), and then to consider the average value of these fatigue limit values. Indeed, the influence of intra-specimen dispersion is not significant enough to justify input data averaging. 


\begin{tabular}{|c|c|c|c|c|c|c|c|c|c|c|c|c|c|}
\hline \multirow{2}{*}{\multicolumn{2}{|c|}{$\begin{array}{l}\text { Number of specimens } \\
\text { Standard deviation of } \\
\text { intra-specimen noise } \\
\left(\mathrm{W} / \mathrm{m}^{3}\right)\end{array}$}} & \multicolumn{3}{|c|}{1} & \multicolumn{3}{|c|}{5} & \multicolumn{3}{|c|}{15} & \multicolumn{3}{|c|}{30} \\
\hline & & 0 & $\begin{array}{c}300 \\
\text { (exp.) }\end{array}$ & 600 & 0 & $\begin{array}{c}300 \\
\text { (exp.) }\end{array}$ & 600 & 0 & $\begin{array}{c}300 \\
\text { (exp.) }\end{array}$ & 600 & 0 & $\begin{array}{c}300 \\
\text { (exp.) }\end{array}$ & 600 \\
\hline \multirow{4}{*}{$\begin{array}{l}\text { Mean } \\
\text { value } \\
(\mathrm{MPa})\end{array}$} & $\sigma_{\mathrm{DB}_{-} 1}$ & 255 & 255 & 255 & 255 & 255 & 255 & 255 & 255 & 255 & 255 & 255 & 255 \\
\hline & $\sigma_{\mathrm{DB} \_2}$ & 254 & 254 & 254 & 254 & 254 & 254 & 254 & 254 & 254 & 254 & 254 & 254 \\
\hline & $\sigma_{\mathrm{DB} \_3}$ & 260 & 261 & 261 & 260 & 260 & 260 & 260 & 260 & 261 & 261 & 261 & 261 \\
\hline & $\sigma_{\mathrm{DB}_{-} 4}$ & 274 & 212 & 149 & 276 & 272 & 225 & 276 & 276 & 269 & 276 & 276 & 276 \\
\hline \multirow{4}{*}{$\begin{array}{c}\text { Standard } \\
\text { deviation } \\
(\mathrm{MPa})\end{array}$} & $S_{\mathrm{DB}_{-} 1}$ & 8 & 8 & 9 & 5 & 5 & 5 & 4 & 4 & 3 & 2 & 2 & 2 \\
\hline & $S_{\mathrm{DB}_{-} 2}$ & 8 & 8 & 9 & 5 & 5 & 5 & 4 & 4 & 3 & 3 & 2 & 2 \\
\hline & $S_{\text {DB_3 }}$ & 10 & 10 & 10 & 8 & 8 & 8 & 8 & 8 & 8 & 8 & 8 & 8 \\
\hline & $S_{\mathrm{DB}_{4} 4}$ & 10 & 86 & 82 & 6 & 24 & 82 & 4 & 4 & 36 & 3 & 3 & 3 \\
\hline
\end{tabular}

Table 5. Influence of the number of "numerical" specimens on the estimation of the fatigue limit. Fatigue limit values were deduced from the four criteria by considering mechanical dissipation values averaged over 1, 5, 15 and 30 specimens. For each criterion, the mean value $\sigma_{\mathrm{DB}_{-} j}$ and standard deviation $S_{\mathrm{DB}_{-} j}$ of the obtained fatigue limit values are derived from 1000 data set generations. Values in bold correspond to results obtained using the experimental intra-specimen noise identified in Fig. 11(d).

\section{Application for the comparison of different printing strategies}

Finally, a practical application was performed to compare different manufacturing strategies from the same maraging steel powder. Four printing strategies were defined:

- Strategy 1 is the one used in the first part of the study. The porosity rate was of $0.07 \%$. The strategy was optimized by the AddUp company for industrial use;

- Strategies 2 and 3 are close to Strategy 1 but they feature small differences in terms of laser path, laser power and scanning speed. The objective is to show if it is possible to distinguish 
such close strategies to Strategy 1 in terms of calorific response due to fatigue damage. Porosity rates were equal to $0.1 \%$ and $0.3 \%$ for Strategies 2 and 3 respectively;

- Strategy 4 corresponds to a higher productivity for the process, involving a higher hatching distance in particular and a significantly higher porosity level, about $15 \%$. Fatigue performances are expected to be much lower than those of the other three strategies.

No annealing or HIP treatment was performed on the specimens. The objective here was to compare the four printing strategies prior to any heat treatment. Fig. 14 shows the calorific responses obtained from these four strategies. Mean values $\sigma_{\mathrm{DB}_{-} 1}$ and uncertainties on the fatigue limits estimated with Criterion 1 are given in Table 6. Assuming a Gaussian distribution, uncertainties were defined from the "99.7" rule:

$$
U= \pm 3 \times \frac{\left(S_{\mathrm{DB}_{1} 1}\right)_{\text {one spec }}}{\sqrt{n_{\text {spec }}}}
$$

where $n_{\text {spec }}$ is the number of specimens tested and $\left(S_{\mathrm{DB}_{1} 1}\right)_{\text {one spec }}$ the standard deviation of the fatigue limit when using one specimen for the identification. This standard deviation was assumed to be independent from the manufacturing process, and therefore defined from Strategy 1: $\left(S_{\mathrm{DB}_{-} 1}\right)_{\text {one spec }}=8 \mathrm{MPa}$ (value as indicated in Table 5). Uncertainty ranges on the fatigue limits are shown on the x-axis of the graph in Fig. 14. The following conclusions can be drawn from Table 6 . Strategies 1 and 4 are clearly the best $\left(\sigma_{\mathrm{DB}_{-} 1}=253 \pm 6 \mathrm{MPa}\right)$ and worst $\left(\sigma_{\mathrm{DB}_{-} 1}=106 \pm 14 \mathrm{MPa}\right)$ respectively. Strategies $2\left(\sigma_{\mathrm{DB}_{-} 1}=225 \pm 14 \mathrm{MPa}\right)$ and $3\left(\sigma_{\mathrm{DB}_{-} 1}=212 \pm 17 \mathrm{MPa}\right)$ appear to be close but slightly worse than Strategy 1 . Considering the intersections or absence thereof between the four uncertainty ranges, it can be noted that that Strategies 1, 3 and 4 are a priori distinct in terms of fatigue performance. Strategy 2 is a priori distinct from Strategy 1, but it would require more tests to distinguish it with a high confidence level from Strategy 3. 


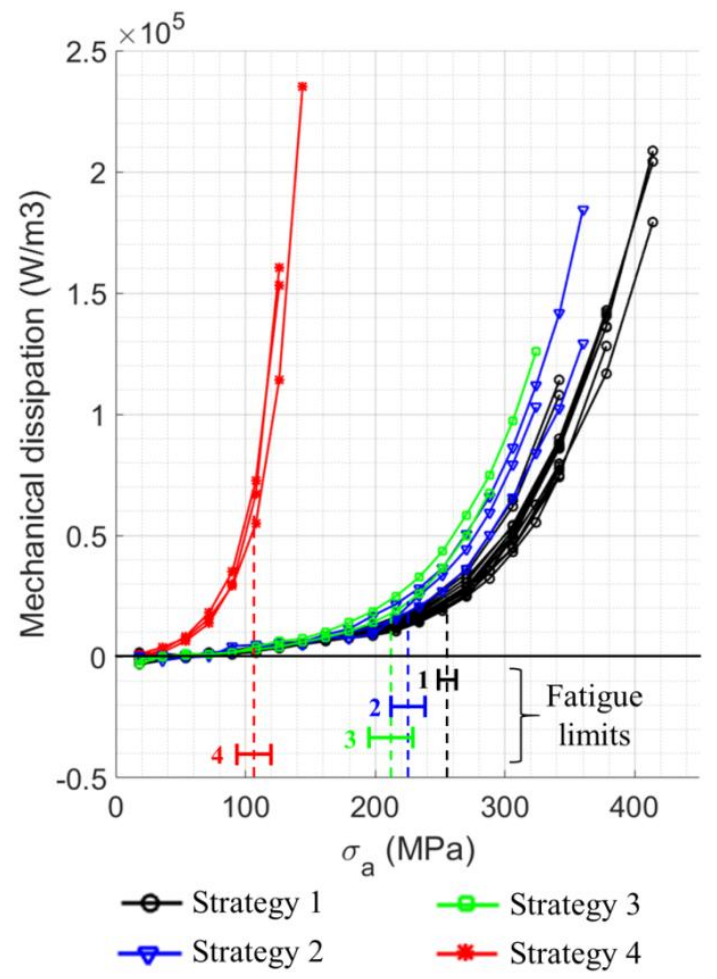

Fig. 14. Application to compare four manufacturing strategies: mechanical dissipation as a function of stress amplitude $\sigma_{\mathrm{a}}$

\begin{tabular}{ccccc}
\hline & Strategy 1 & Strategy 2 & Strategy 3 & Strategy 4 \\
\hline $\begin{array}{l}\text { Mean value } \sigma_{\text {DB_1 }} \\
\text { of the fatigue limit }\end{array}$ & $255 \mathrm{MPa}$ & $225 \mathrm{MPa}$ & $212 \mathrm{MPa}$ & $106 \mathrm{MPa}$ \\
$\begin{array}{c}\text { Number } n_{\text {spec }} \text { of } \\
\text { specimens tested }\end{array}$ & 14 & 3 & 2 & 3 \\
Uncertainty & $+/-6 \mathrm{MPa}$ & $+/-14 \mathrm{MPa}$ & $+/-17 \mathrm{MPa}$ & $+/-14 \mathrm{MPa}$
\end{tabular}

Table 6. Fatigue limit obtained from calorimetric data using Criterion 1 for four different manufacturing strategies. 


\section{Conclusion}

A method for the rapid and reliable characterization of the calorimetric signature of fatigue damage was proposed and tested on maraging steel manufactured using the L-PBF process. The method requires thermographic measurements with specific thermal acquisition and HSR processing in order to extract the mechanical dissipation associated with fatigue damage. In particular, real-time averaging over entire numbers of mechanical cycles enabled us to advantageously remove the influence of thermoelastic coupling. Conventional fatigue tests were also performed to plot S-N data. Two main conclusions can be drawn from the study:

- two distinct populations among the printed specimens were identified, depending on their locations on the building plate, which could be explained by an effect of the direction of powder deposition or gas flow;

- from fatigue tests instrumented by IR camera, a repeatability study with statistical analysis enabled us to propose a model for mechanical dissipation behavior as a function of stress amplitude. Inter- and intra-specimen parameters were characterized. Several fatigue limit assessment criteria were compared in terms of precision and robustness. The comparison of different manufacturing strategies from the same maraging steel powder showed that distinct manufacturing strategies lead to different mechanical dissipation values, and thus to different fatigue limits.

It can be recalled that a spatial averaging of the thermal data over the gauge section of the specimen enabled us to measure a macroscopic calorific signature of the fatigue damage. The measured mechanical dissipation can be considered as being associated with the mean fatigue damage occurring in the specimen, involving a priori homogeneously-distributed porosities with limited impact from localized defects (especially critical surface defects). The interest of the proposed experimental methodology could be therefore to "rapidly" optimize printing strategies with regard to the fatigue performance of the bulk material, without being penalized by localized defects. 


\section{Funding:}

This work was supported by the Région Auvergne Rhône Alpes (Ressourcement en fabrication additive), France.

\section{Acknowledgments:}

Dr. Cécile Mattrand, Associate-Professor at the Sigma-Clermont engineering school, is gratefully acknowledged for her help in the statistical analysis of the mechanical dissipation behavior model.

\section{References}

[1] ISO/ASTM 52900:2015, Additive manufacturing - General principles - Terminology, 2015. https://www.iso.org/standard/69669.html

[2] M. Mani, B. Lane, M.A. Donmez, S.C. Feng, S.P. Moylan, R. Fesperman, Measurement Science Needs for Real-time Control of Additive Manufacturing Powder Bed Fusion Processes; NIST Interagency/Internal Report (NISTIR) - 8036. Feb. 2015. http://dx.doi.org/10.6028/NIST.IR.8036

[3] D. Herzog, V. Seyda, E. Wycisk, C. Emmelmann, Additive manufacturing of metals, Acta Mater. 117 (2016) 371-392. https://doi.org/10.1016/j.actamat.2016.07.019

[4] T. Debroy, H.L. Wei, J.S. Zuback, T. Mukherjee, J.W. Elmer, J.O. Milewski, A.M Beese, A. Wilson-Heid, A. De, W. Zhang. Additive manufacturing of metallic components - Process, structure and properties, Prog. Mater. Sci. 92 (2018) 112-224. https://doi.org/10.1016/j.pmatsci.2017.10.001

[5] R. Shrestha, J. Simsiriwong, N. Shamsaei, Fatigue behavior of additive manufactured 316L stainless steel parts: Effects of layer orientation and surface roughness, Addit. Manuf. 28 (2019) 23-38. https://doi.org/10.1016/j.addma.2019.04.011

[6] R. Biswal, A.K. Syed, X. Zhang, Assessment of the effect of isolated porosity defects on the fatigue performance of additive manufactured titanium alloy, Addit. Manuf. 23 (2018) 433-442. https://doi.org/10.1016/j.addma.2018.08.024

[7] N. Shamsaei, A. Yadollahi, L. Bian, S.M. Thompson, An overview of Direct Laser Deposition for additive manufacturing; Part II: Mechanical behavior, process parameter optimization and control, Addit. Manuf. 8 (2015) 12-35. https://doi.org/10.1016/j.addma.2015.07.002 
[8] A. Yadollahi, N. Shamsaei N, Additive manufacturing of fatigue resistant materials: Challenges and opportunities, Int. J. Fatigue 98 (2017); 14-31. https://doi.org/10.1016/j.ijfatigue.2017.01.001

[9] H. Masuo, Y. Tanaka, S. Morokoshi, H. Yagura, T. Uchida, Y. Yamamoto, Y. Murakami. Influence of defects, surface roughness and HIP on the fatigue strength of Ti-6Al-4V manufactured by additive manufacturing, Int. J. Fatigue 117 (2018) 163-179. https://doi.org/10.1016/j.ijfatigue.2018.07.020

[10] J. Günther, D. Krewerth, T. Lippmann, S. Leuders, T. Tröster, A. Weidner, H. Biermann, T. Niendorf. Fatigue life of additively manufactured Ti-6Al-4V in the very high cycle fatigue regime, Int. J. Fatigue 94 (2017) 236-245. https://doi.org/10.1016/j.ijfatigue.2016.05.018

[11] S. Tammas-Williams, P.J. Withers, I. Todd, P.B. Prangnell, The Influence of Porosity on Fatigue Crack Initiation in Additively Manufactured Titanium Components, Sci. Rep. 7 (2017) 1-13. https://doi.org/10.1038/s41598-017-06504-5

[12] S. Afkhami, M. Dabiri, S.H. Alavi, T. Björk, A. Salminen, Fatigue characteristics of steels manufactured by selective laser melting, Int. J. Fatigue 122 (2019) 72-83. https://doi.org/10.1016/j.ijfatigue.2018.12.029

[13] Y. Bai, D. Wang, Y. Yang, H. Wang, Effect of heat treatment on the microstructure and mechanical properties of maraging steel by selective laser melting, Mater. Sci. Eng. A 760 (2019) 105-117. https://doi.org/10.1016/j.msea.2019.05.115

[14] T.H Becker, D. Dimitrov, The achievable mechanical properties of SLM produced Maraging Steel 300 components, Rapid Prototyp. J. 22 (2016) 487-494. https://doi.org/10.1108/RPJ-08-2014-0096

[15] D. Croccolo, M. De Agostinis, S. Fini, G. Olmi, A. Vranic, S. Ciric-Kostic, Influence of the build orientation on the fatigue strength of EOS maraging steel produced by additive metal machine, Fatigue Fract. Eng. Mater. Struct. 39 (2016) 637-647. https://doi.org/10.1111/ffe.12395

[16] K. Kempen, E. Yasa, L. Thijs, J. Kruth, J. Van Humbeeck, Microstructure and mechanical properties of Selective Laser Melted, Phys. Procedia 12 (2011) 255-263. https://doi.org/10.1016/j.phpro.2011.03.033

[17] G. Meneghetti, D. Rigon, C. Gennari, An analysis of defects influence on axial fatigue strength of maraging steel specimens produced by additive manufacturing, Int. J. Fatigue 118 (2019) 54-64. https://doi.org/10.1016/j.ijfatigue.2018.08.034

[18] J. Song, Q. Tang, Q. Feng, S. Ma, R. Setchi, Y. Liu, Q. Han, X. Fan, M. Zhang, 2019, Effect of heat treatment on microstructure and mechanical behaviours of $18 \mathrm{Ni}-300$ maraging steel manufactured by selective laser melting, Opt. Laser Technol. 120. 105725. https://doi.org/10.1016/j.optlastec.2019.105725 
[19] C.E. Stromeyer, The determination of fatigue limits under alternating stress conditions, Proc. R. Soc. Lond. A 90 (1914) 411-425. https://doi.org/10.1098/rspa.1914.0066

[20] M.P. Luong, Infrared thermographic scanning of fatigue in metals, Nucl. Eng. Des. 158 (1995) 363-376. https://doi.org/10.1016/0029-5493(95)01043-H

[21] M.P. Luong, Fatigue limit evaluation of metals using an infrared thermographic technique, Mech. Mater. 28 (1998) 155-163. https://doi.org/10.1016/S0167-6636(97)00047-1

[22] G. La Rosa, A. Risitano, Thermographic methodology for rapid determination of the fatigue limit of materials and mechanical components, Int. J. Fatigue 22 (2000) 65-73. https://doi.org/10.1016/S01421123(99)00088-2

[23] C. Doudard, S. Calloch, F. Hild, P. Cugy, A. Galtier, Identification of the scatter in high cycle fatigue from temperature measurements, C. R. Mécanique 332 (2004) 795-801. https://doi.org/10.1016/j.crme.2004.06.002

[24] C. Doudard, S. Calloch, P. Cugy, A. Galtier, F. Hild, A probabilistic two-scale model for high-cycle fatigue life predictions, Fatigue Fract. Eng. Mater. Struct. 28 (2005) 279-288. https://doi.org/10.1111/j.14602695.2005.00854.x

[25] R. Munier, C. Doudard, S. Calloch, B. Weber, Determination of high cycle fatigue properties of a wide range of steel sheet grades from self-heating measurements, Int. J. Fatigue 63 (2014) 46-61. https://doi.org/10.1016/j.ijfatigue.2014.01.004

[26] R. Munier, C. Doudard, S. Calloch, B. Weber, Identification of the micro-plasticity mechanisms at the origin of self-heating under cyclic loading with low stress amplitude, Int. J. Fatigue 103 (2017) 122-135. https://doi.org/10.1016/j.ijfatigue.2017.05.027

[27] Z. Teng, H. Wu, C. Boller, P. Starke, Thermography in high cycle fatigue short-term evaluation procedures applied to a medium carbon steel, Fatigue Fract. Eng. Mater. Struct. (2019) https://doi.org/10.1111/ffe.13136

[28] A. Akai, D. Shiozawa, T. Yamada, T. Sakagami, Energy Dissipation Measurement in Improved Spatial Resolution Under Fatigue Loading, Exp. Mech. (2019). https://doi.org/10.1007/s11340-019-00552-w

[29] Y. Cao, Z. Moumni, J. Zhu, Y. Zhang, Y. You, W. Zhang, 2020. Comparative investigation of the fatigue limit of additive-manufactured and rolled 316 steel based on self-heating approach, Eng. Fract. Mech. 223, 106746. https://doi.org/10.1016/j.engfracmech.2019.106746 
[30] A. Chrysochoos, R. Peyroux, Experimental analysis and numerical simulation of thermomechanical couplings in solid materials, Rev. Générale Therm. 37 (1998) 582-606. https://doi.org/10.1016/S00353159(98)80036-6

[31] T. Boulanger, A. Chrysochoos, C. Mabru, A. Galtier, Calorimetric analysis of dissipative and thermoelastic effects associated with the fatigue behavior of steels, Int. J. Fatigue 26 (2004) 221-229. https://doi.org/10.1016/S0142-1123(03)00171-3

[32] B. Ferrar, L. Mullen, E. Jones, R. Stamp, C.J. Sutcliffe, Gas flow effects on selective laser melting (SLM) manufacturing performance, J. Mater. Process. Technol. 212 (2012) 355-364. https://doi.org/10.1016/j.jmatprotec.2011.09.020

[33] S. Ly, A.M. Rubenchik, S.A. Khairallah, G. Guss, M.J. Matthews, Metal vapor micro-jet controls material redistribution in laser powder bed fusion additive manufacturing, Sci. Rep. 7 (2017) 1-12. https://doi.org/10.1038/s41598-017-04237-z

[34] ISO 7500-1:2018, Metallic materials - Calibration and verification of static uniaxial testing machines Part 1: Tension/compression testing machines - Calibration and verification of the force-measuring system, 2018. https://www.iso.org/standard/72572.html

[35] ISO 1099:2017, Metallic materials - Fatigue testing - Axial force-controlled method, 2017. https://www.iso.org/standard/67847.html

[36] D. Delpueyo, X. Balandraud, M. Grédiac, S. Stanciu, N. Cimpoesu, 2018. A specific device for enhanced measurement of mechanical dissipation in specimens subjected to long-term tensile tests in fatigue, Strain 54, e12252. https://doi.org/10.1111/str.12252

[37] G.W. Snedecor, W.G. Cochran, Statistical Methods, 8th ed., Iowa State University Press, Ames, Iowa, 1989.

[38] P. Bonnet, X. Hermite, I. Huther, F. Lefebvre, Guide pour le choix d'une méthode d'essais de fatigue et de l'analyse statistique associée - Collection Performances - Fatigue, CETIM, Senlis, France, 2016.

[39] A. Chrysochoos, H. Louche, An infrared image processing to analyse the calorific effects accompanying strain localization, Int. J. Eng. Sci. 38 (2000) 1759-1788. https://doi.org/10.1016/S0020-7225(00)00002-1

[40] J.M. Dulieu-Barton, P. Stanley, Development and applications of thermoelastic stress analysis, J. Strain Anal. Eng. Des. 33 (1998) 93-104. https://doi.org/10.1243/0309324981512841 
[41] P. Jongchansitto, C. Douellou, I. Preechawuttipong, X. Balandraud, 2019. Comparison between 0D and 1D approaches for mechanical dissipation measurement during fatigue tests, Strain 55, e12307. https://doi.org/10.1111/str.12307

[42] J. Huang, M.L. Pastor, C. Garnier, X. Gong, Rapid evaluation of fatigue limit on thermographic data analysis, Int. J. Fatigue 104 (2017) 293-301. https://doi.org/10.1016/j.ijfatigue.2017.07.029

[43] C. Douellou, X. Balandraud, E. Duc, B. Verquin, F. Lefebvre, F. Sar, Fast fatigue characterization by infrared thermography for additive manufacturing, in: F. Lefebvre, P. Souquet (Eds.), Fatigue Design 2019, International Conference on Fatigue Design, 8th Edition, November 20-21, 2019, Senlis, France. Procedia Structural Integrity 19; 2019, pp. 90-100. https://doi.org/10.1016/j.prostr.2019.12.011 